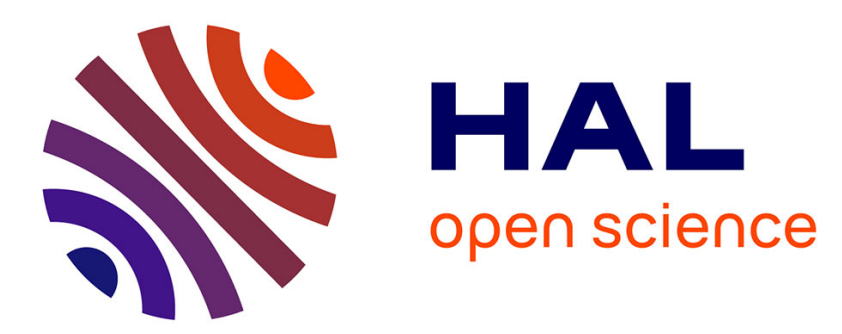

\title{
Islands as eddy transformation and generation hotspots: Cabo Verde case study
}

Cláudio Cardoso, Rui M A Caldeira, Paulo Relvas, Alexandre Stegner

\section{To cite this version:}

Cláudio Cardoso, Rui M A Caldeira, Paulo Relvas, Alexandre Stegner. Islands as eddy transformation and generation hotspots: Cabo Verde case study. Progress in Oceanography, 2020, 184, pp.102271. 10.1016/j.pocean.2020.102271 . hal-03028622

\section{HAL Id: hal-03028622 \\ https://hal.sorbonne-universite.fr/hal-03028622}

Submitted on 27 Nov 2020

HAL is a multi-disciplinary open access archive for the deposit and dissemination of scientific research documents, whether they are published or not. The documents may come from teaching and research institutions in France or abroad, or from public or private research centers.
L'archive ouverte pluridisciplinaire HAL, est destinée au dépôt et à la diffusion de documents scientifiques de niveau recherche, publiés ou non, émanant des établissements d'enseignement et de recherche français ou étrangers, des laboratoires publics ou privés. 


\title{
Islands as eddy transformation and generation hotspots: Cape Verde case study
}

\author{
Cláudio Cardoso ${ }^{\mathrm{a}, *}$, Rui. M. A. Caldeira ${ }^{\mathrm{a}, \mathrm{b}}$, Paulo Relvas ${ }^{\mathrm{c}}$, Alexandre Stegner ${ }^{\mathrm{d}, \mathrm{e}}$ \\ ${ }^{a}$ Agência Regional para o Desenvolvimento da Investigacão Tecnologia e Inovacão, OOM, Funchal - Portugal \\ ${ }^{b}$ IDL, University of Lisbon, Lisbon, Portugal \\ ${ }^{c}$ Center of Marine Sciences (CCMAR/FCT), Universidade do Algarve, Campus de Gambelas, Faro, Portugal \\ ${ }^{d}$ Laboratoire de Météorologie Dynamique, École Polytechnique, Palaiseau, France \\ ${ }^{e} U M E$, ENSTA-ParisTech, Paris, France
}

\begin{abstract}
The characterisation of incoming background and island-induced mesoscale eddies in the Cape Verde Archipelago is discussed herein. Special attention is given to the interaction of background eddies with the islands topography and orographic winds, along with the interaction and potential impacts on the generation of island-induced eddies. Some examples of the local biological response to background and island-induced eddies are given. This is achieved by combining remote-sensing satellite observations for wind, Sea Surface Height and Chlorophyll $a$ (Chl $a$ ) surface concentrations. Results show that the interaction between incoming background eddies and the archipelago is a recurrent phenomenon, which results in eddy deflection, splitting, merging, intensification and termination. Local island-induced disturbances are also significant, mainly due to atmospheric effects. Such processes result in the generation of island-induced eddies and in wind-mediated eddy intensification and confinement, more often observed in the leeward group. It is strongly suggested that many of the local island-induced eddies are a direct product or a by-product of the interaction of background eddies with the archipelago. In respect to the biological realm, background eddies are often associated with enhanced Chla. However, nutrient-injection by a (background related) island-induced cyclonic eddy is observed to originate a pronounced phytoplankton bloom in the vicinity of the tallest island. Such observations challenge the idea that local biological productivity in deep oceanic islands are exclusively driven by island-induced mechanisms.
\end{abstract}

Keywords: Eddy-island interactions, Island-induced eddies, Wind-mediated eddy intensification and Confinement, Island Wake, Island mass effect

\section{Introduction}

It has been well established that oceanic eddies are ubiquitous features in the world's oceans. In simple terms, an eddy is defined as a self-rotating coherent body of wa5 ter which propagates through the ocean mostly from self- ${ }^{25}$ advection and planetary vorticity effects (Cushman-Roisin et al., 1990; Chelton et al., 2011), though several other factors can influence their propagation (e.g. Simmons \& Nof, 2000; Cenedese, 2005; Andres \& Cenedese, 2013; Sangrà

10 et al., 2009; Holland \& Mitchum, 2001). Reported to ${ }^{30}$ be the dominant source of kinetic energy in the oceans (Chelton et al., 2011), eddies can trap and transport water with distinct properties in their cores for long distances (Alpers et al., 2013; Romero et al., 2016), being even able

15 to go across fronts (Barton, 1987). In that sense, ed- ${ }^{35}$ dies generated in upwelling regions can be characterised by nutrient-rich waters, that under favourable conditions enhance biological productivity even in presumably oligotrophic regions (Löscher et al., 2015; Romero et al., 2016)

\footnotetext{
* Corresponding author

Email address: claudio.cardoso@oom.arditi.pt (Cláudio Cardoso)
}

20 and are thus potentially favourable for fish larval survival, acting as a medium for transportation and colonization (Condie \& Condie, 2016). On the other hand, eddies can be characterised by oxygen-depleted waters that create "dead-zones" in the middle of the ocean (Karstensen et al., 2015; Hauss et al., 2016; Schütte et al., 2016b). Apart from the horizontal advection, vertical motion in the interior of eddies lead to upwelling/downwelling in cyclonic/anticyclonic eddies due to the divergent/convergent movement of water at the surface, which uplifts/deepens the thermocline and thus enhances/decreases nutrient availability through self-induced Ekman suction/pumping mechanisms. For cyclonic eddies, this mechanism is an important source of cold, nutrient-rich water to the euphotic zone (Hasegawa et al., 2009), which in turn benefits primary productivity and drives the local increase of Chlorophyll $a(\mathrm{Chl} a)$ at the surface (Andrade et al., 2014; Alpers et al., 2013; Romero et al., 2016). Anticyclonic eddies do exactly the opposite, as they converge and inject water from surface to deeper layers. However, this simplistic view of anticyclonic eddies has been challenged in recent years (e.g. Dufois et al., 2016; Martin \& Richards, 2001; McGillicuddy et al., 2007; Gaube et al., 2015; Brannigan, 2016). 
Eddy generation can be driven by various physical mechacting in the ocean, such as: topography effects (Pattiaratchi et al., 1987; Heywood et al., 1990); current shear (Chelton et al., 2011; Schütte et al., 2016a); atmosphereocean interaction (Alpers et al., 2013; Ioannou et al., 2017; Wilson, 2016; Xu et al., 2016); eddy-eddy interactions 50 (Sangrà et al., 2009; Chelton et al., 2011); among others. In this study we focus specifically on eddy generation through island-induced processes, which result from the complex interaction of several mechanisms. Barkley (1972) introduced the first empirical case study of an island-induced 55 eddy through observations of fishing gear drift and surface currents measurements at Johnston Atoll. From the oceanographic point of view, the blocking effect induced by an island (or group of islands) generates a wake flanked by a turbulent area in the opposite side of the impinging flow 60 (Stegner, 2014; Tomczak, 1988; Spedding, 2014) that can extend several island diameters downstream and is often associated with the generation of eddies (Hasegawa et al., 2009; Caldeira et al., 2005; Heywood et al., 1990; Barton, 2001). The scale of the eddies at their initial phase is nor65 mally not far from the diameter of the island which provoked it (Arístegui et al., 1994; Dong et al., 2007; Sangrà et al., 2009).

Oceanic islands can in the same manner disrupt the atmospheric flow, generating one of the most remarkable and

70 distinct island-induced features in the adjacent environment - a Von Kaman Vortex Street (Fig. 1). This occurs when the incident winds are forced to contour the islands, creating sheltered regions and a vortex-like train of clouds (Chopra \& Hubert, 1964; Caldeira et al., 2002; Couvelard 75 et al., 2012; Spedding, 2014). This wind wake normally extends a few thousand kilometres from the island in the prevailing wind direction (leeward). The local oceanic response may be superficial, with the development of a diurnal thermocline in the sheltered region (Barton et al.,

so 2000; Caldeira et al., 2002, 2005). In the case of persistent steady winds, sharp horizontal wind shear lines may form at the edges of the wake, resulting in rapid variations in the Ekman transport (Barton, 2001; Yoshida et al., 2010). As a consequence, the upwelling of deeper waters must com85 pensate the wind-driven surface divergence at the western boundary of the lee - elevating the pycnocline - while at the eastern boundary, sinking of surface water through ${ }^{120}$ Ekman pumping occurs as a product of the wind-driven surface convergence - deepening the pycnocline (Chavanne 90 et al., 2002; Basterretxea et al., 2002). Ultimately, these mechanisms lead to the formation of both cold-core, cyclonic and warm-core, anticyclonic mesoscale features in ${ }^{125}$ the lee of the islands (Nencioli et al., 2008; Dong et al., 2009; Jia et al., 2011).

For islands with high mountains where the prevailing wind is parallel to the dominant ocean current, it is difficult to access the nature of the eddies that are generated downstream, i.e. from current or wind induced processes (Barton, 2001). In Hawaii, Dickey et al. (2008) concluded

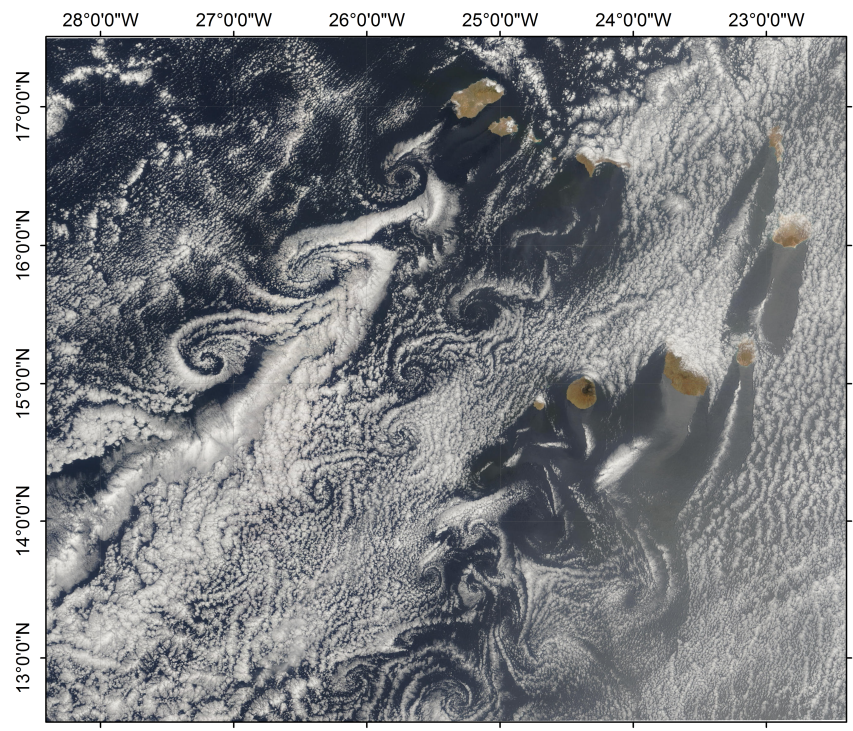

Figure 1: Atmospheric Von Karman Vortex Streets induced by the Cape Verde Archipelago on April 26, 2004. Data Source: MODIS Rapid Response Team, NASA/GSFC.

that the impinging flow was too weak for the generation of the sampled eddies, attributing the main cause to the local strong trade winds blowing through a narrow channel between the two tallest islands of the archipelago. In Canary Islands, Arístegui et al. (1994) noticed the presence of cyclonic and anticyclonic eddies downstream of Gran Canaria and suggested that these were most likely provoked by the island's blocking effect on the oceanic flow, since eddies are recurrent even during periods of low wind intensity. Although the latter was further confirmed by Jiménez et al. (2008), one must consider the possibility that wind and current island-induced disturbances can act as coupled mechanisms and thus can enhance or suppress the production of eddies in such systems (Sangrà et al., 2007), especially when the two are not capable of acting alone (Barton et al., 2000; Basterretxea et al., 2002; Piedeleu et al., 2009).

Naturally, such island-induced physical mechanisms must be reflected in the biological realm. Island Mass Effect (IME) was first introduced by Doty \& Oguri (1956) as an increase in $\mathrm{Chl} a$ in the waters surrounding the Hawaiian Archipelago. This concept was later generalized to include bathymetry-induced island effects on the local oceanography (Hamner \& Hauri, 1981) and is now associated with island-induced eddies that bring nutrients to the euphotic zone and consequently enhance local primary productivity (e.g. Arístegui et al., 1994; Caldeira et al., 2014, 2002; Hasegawa et al., 2009; Andrade et al., 2014; Coutis \& Middleton, 2002). IME can still be fuelled by several landborn factors such as the input of macro and micronutrients from island runoff (Dandonneau \& Charpy, 1985; Bell, 1992) and groundwater discharges (Hwang et al., 2005; Tait et al., 2014; Gove et al., 2016) or contributions from 
benthic processes (Doty \& Oguri, 1956; Dandonneau \& Charpy, 1985). For this reason, it is very important to clarify the nature of the driving mechanisms, but more importantly, one should not neglect the regional oceanographic/atmospheric context to which an island is exposed ${ }_{190}$ to.

Eddy intensification, deflection, splitting and termination have been reported to occur when interacting with islands or seamounts (e.g. Cenedese, 2002, 2005; Andres \& Cenedese, 2013; Simmons \& Nof, 2000; Chang et al., 2012; Yang et al., 2017). Nevertheless, background eddyisland interaction has seldom been considered when asimplications of such features in near-field processes remain poorly documented and, as Dong et al. (2007) suggested, further studies should be conducted to better understand the physical processes occurring in a real oceanic island wake.

Hence, two key questions are proposed: do background incoming eddies have considerable interactions with oceanic islands which have been neglected to present date? And if so, to what extend can islands impact the structure and propagation of such features? Our study aims to fill this gap and thus better comprehend the relation between background and island-induced eddies in the Cape Verde Archipelago between the years 2003-2014. Special attention is given to the archipelago's exposure to background incoming eddies, the interaction of such features with the islands, consequent implications in the generation of island-induced eddies, and the influence of islandinduced atmospheric effects in the propagation of both background and island-induced eddies. Background edare defined as those which are generated outside but intersect the delimited near-field area (CV area), set between $22.5-26.5^{\circ} \mathrm{W}$ and $13.5-17.5^{\circ} \mathrm{N}$ (doted black area in Fig. 3), whilst island-induced eddies are the ones generated within $\mathrm{CV}$ area. As a complementary investigation, ome examples representative of the biological response to these eddies are discussed. This paper is organized as follows: a brief review concerning the regional setting is presented in Section 2; the data being used, along with the processing methods follows is discussed in Section 3;

175 main results and subsequent discussion are presented in Section 4; whereas the summary and main conclusions are addressed in Section 5.

\section{Geographic setting}

Cape Verde is an archipelago with 10 deep-water islands located in the northeast Atlantic Ocean, 450-600 km off the western African coast. The archipelago is arrayed in a west-facing horseshoe disposition and can be divided in ${ }^{210}$ two main groups (Fig. 2): the windward (northern) and the leeward (southern) islands. In terms of geomorphol- main structures, characterised by shallow depths between islands: the northern chain, with a west-east orientation (from Santo Antão to São Nicolau); and the east-southwest chain, formed by two detached edifices (from Sal to Santiago and from Fogo to Brava; Ramalho, 2011). The João Valente bank, situated between Boa Vista and Maio islands, is characterised by very shallow depths where the highest summit reaches $14 \mathrm{~m}$ depth (Fig. 2; Ramalho, 2011). Such geomorphological disposition may lead the easternmost islands to act as a single attached edifice, obstructing the westward propagation of incoming eddies.

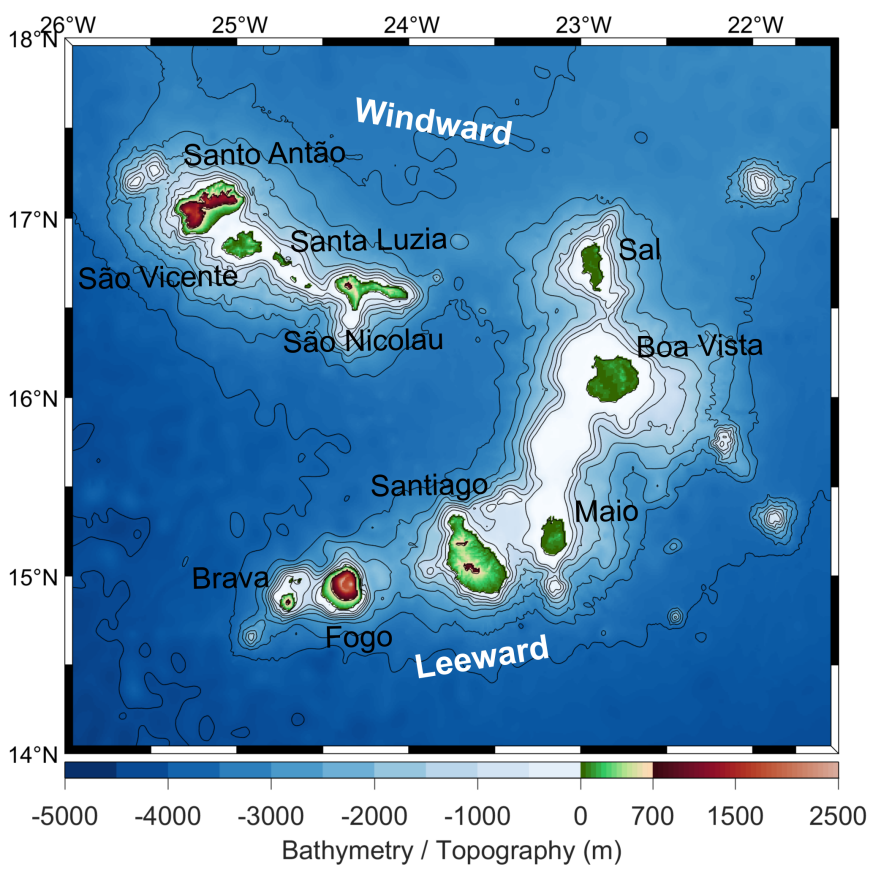

Figure 2: Bathymetry and topography of the Cape Verde archipelago, with the identification (black) and grouping (white) of the islands. Bathymetry isolines have a 500-m interval. The redbased colormap is used for $\geq 700 \mathrm{~m}$ topography, representative of the maximum typical altitude of the atmospheric inversion layer (Chavanne et al., 2002). Datasource: SRTM 30 m.

The archipelago's regional context is characterised by the interaction of large-scale currents and features (Fig. 3 ), strongly affected by the seasonal meridional migration of the Intertropical Convergence Zone (ITCZ; Stramma \& Schott, 1999). The southern limit of the Canary Current (CC) transports cold water from north to south off the African coast, turning south-westward near Cape Blanc to become the North Equatorial Current (NEC Mittelstaedt, 1983, 1991; Stramma et al., 2005). NEC is characterised by a $10-15 \mathrm{~cm} \mathrm{~s}^{-1}$ mean speed with a dominant west/north-westward direction (Stramma \& Siedler, 1988; Zhang et al., 2003), reaching its maximum speed in summer and weakening during winter (Fig. 4 bottom pannels; Arnault, 1987). With an eastward mean flow speed of $\approx 42 \mathrm{~cm} \mathrm{~s}^{-1}$ (Fratantoni, 2001), the North Equatorial Counter-Current (NECC) is particularly strong during summer and early fall (Arnault, 1987; Mittelstaedt, 1991), 
when the ITCZ reaches its northernmost position (Lázaro 2005). It is also during this period that NECC is most likely to have an influence in the Cape Verde Archipelago (Fernandes et al., 2005). The Mauritanian Current (MC) is the northern branch followed by the interception of NECC with the African coast. It reaches to the relaxation of the trade winds (Fig. $4 \mathrm{c}$ and $\mathrm{d}$ ) and consequent northward displacement and strengthening of NECC, it extends up to $\approx 20^{\circ} \mathrm{N}$ during summer/early autumn (Fig. $4 \mathrm{~g}$ and $\mathrm{h}$ ), being partly responsible for the 1991). Southwest of the archipelago, the Guinea Dome (GD) is a permanent cyclonic geostrophic feature, associated with the NEC, NECC and the North Equatorial Undercurrent (Siedler et al., 1992). It is defined by a dome of the isotherms and low hydrostatic pressure (Faye et al., 2015), developed by divergent wind-stress curl (Richardson, 1983; Siedler et al., 1992).

Additionally, two different water masses near Cape Blanc, crossing the archipelago and extending the entire length of Atlantic Ocean (Emery, W. J., Meincke, 1986; Lozier et al., 1995), forming a basin-wide frontal system coined by Zenk et al. (1991) as the Cape Verde Frontal Zone (CVFZ). This front is marked by strong thermohaline (Zhang et al., 2003) and even larger inorganic nutrients and dissolved 240 oxygen gradients (Pelegrí \& Peña-Izquierdo, 2015), separating the warmer and saltier North Atlantic Central Water from the cooler, fresher and richer in nutrients South Atlantic Central Water (Mittelstaedt, 1983, 1991; Meunier et al., 2012; Pérez-Rodríguez et al., 2001). Albeit the strong gradients $\left(\geq 3^{\circ} \mathrm{C}\right.$ and $0.9 \mathrm{psu}$ in $10 \mathrm{~km}$; Bar-275 ton, 1987), this front is characterised by strong horizontal exchange of heat by double diffusion and is densitycompensated, thus undetectable in the density field (Zenk et al., 1991; Pastor et al., 2008).

The northerly trade winds driven by the Azores high ${ }^{280}$ - equatorial low pressure cell generate large scale divergent Ekman transport along the western African coast (Fig. 4 upper panels; Mittelstaedt, 1983), leading to one of the strongest and most productive upwelling systems in the world - the Canary Current Upwelling System. Coastal upwelling is permanent between $20^{\circ}-25^{\circ} \mathrm{N}$, reaching its maximum intensity during spring and autumn (Mittelstaedt, 1991; Ould-Dedah et al., 1999). South of $20^{\circ} \mathrm{N}$, this phenomenon only occurs during winter/early spring (Fig. 4e and f, respectively; Van Camp et al., 1991; Nykjær \& Van Camp, 1994; Lázaro et al., 2005) and is strongly associated with the local enhancement of biological productivity (Pelegrí et al., 2006; Lathuilière et al., 2008; Demarcq \& Somoue, 2015), partially driven by the southward transport of cold, nutrient-rich water from the CC (Mittelstaedt, 1991). The strength and seasonal oscillation of the coastal upwelling depends mainly on the alongshore wind-stress seasonal patterns (Fig. 4 upper panels; Hagen, 2001; Pradhan et al., 2006) and on the

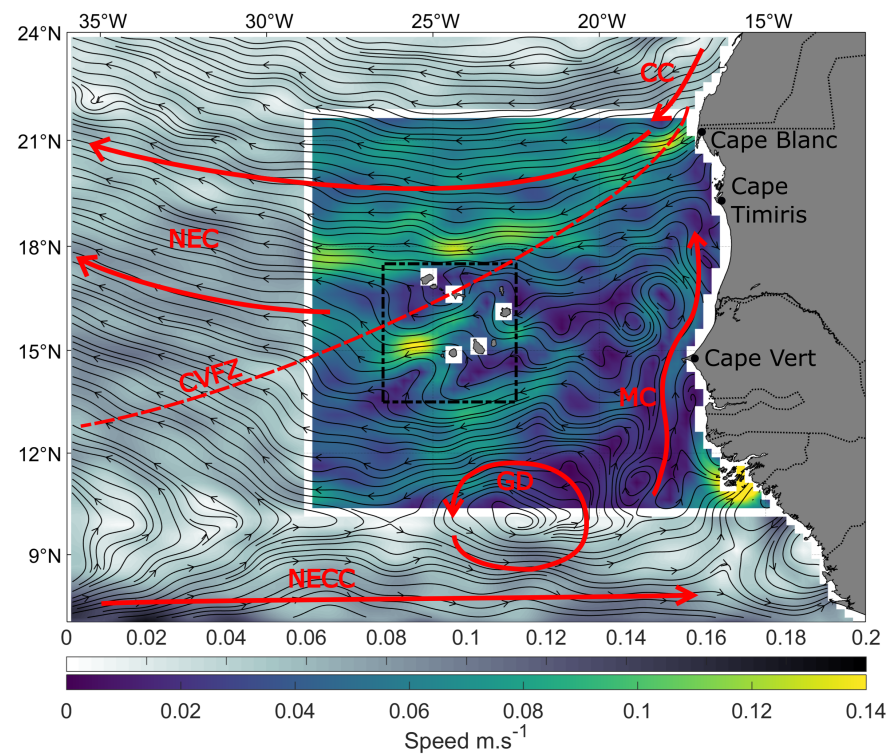

Figure 3: Mean surface ocean currents and features (2003-2014): CC - Canary Current; NEC - North Equatorial Current; NECC North Equatorial Counter-Current; MC - Mauritania Current; GD - Guinea Dome; CVFZ - Cape Verde Frontal Zone. Doted area represents the near-field $(\mathrm{CV})$ area. Grey and coloured colormap (with different scales) represent the exterior and interior of the study area, respectively. Data: GlobCurrent V2.0 Total 15m.

seasonal variation of the $\mathrm{MC}$ extension (Fig. $4 \mathrm{~g}$ and $\mathrm{h}$; Mittelstaedt, 1991; Siedler et al., 1992).

Naturally, the Cape Verde archipelago is under the direct influence ITCZ and subjected to prevailing northeast trade winds throughout the year, with higher intensity during winter and spring $\left(9.5 \mathrm{~m} \mathrm{~s}^{-1}\right.$ maximum mean speed, Fig. 4a and b; Lázaro et al., 2005; Varela-Lopes \& Molion, 2014). Evidences of a shadow effect induced by the islands topography was first demonstrated by Chavanne et al. (2002), when a wake of weak winds, flanked by strong winds, was observed in the lee of all the major islands. Subsequently, Chelton (2004) and Chaigneau et al. (2009) demonstrated that this effect is still perceivable at a regional scale, with distinct dipoles of positive and negative wind curl extending several hundred kilometres downwind. It is well established that this mechanism can drive the generation of eddies in the island(s) wake (Calil et al., 2008; Jiménez et al., 2008; Jia et al., 2011; Couvelard et al., 2012; Yoshida et al., 2010; Caldeira et al., 2014). Furthermore, some authors argue that these processes are enhanced when the steady wind is capped by an atmospheric inversion layer (e.g. Barton et al., 2000; Hafner \& Xie, 2003). According to Chavanne et al. (2002) this condition is well met in the Cape Verde Islands, where it is possible to find strong and steady winds combined with high topography (1500-2800 m, Fig. 2), well above the typical inversion layer $(500-700 \mathrm{~m})$. 


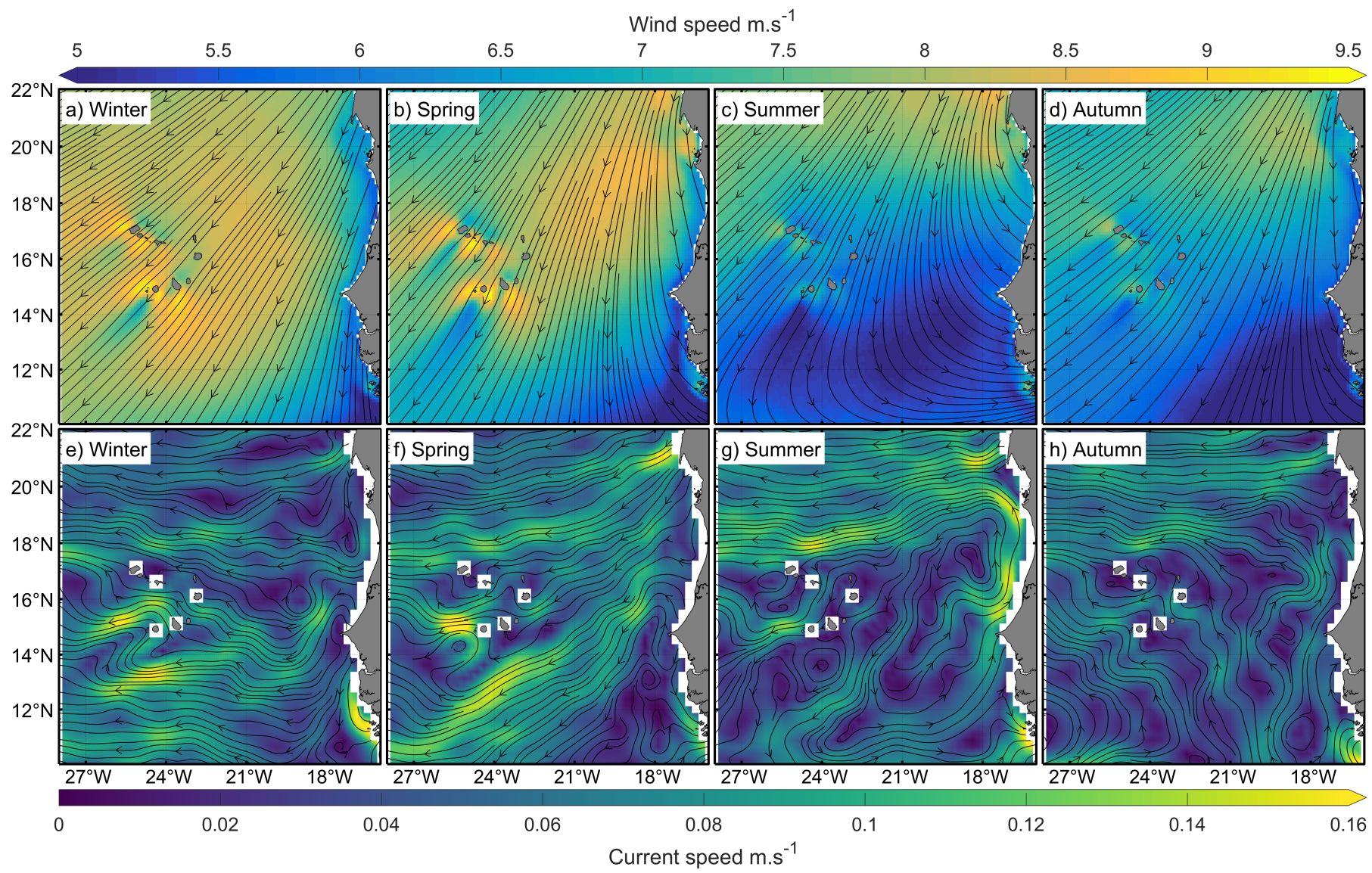

Figure 4: Seasonal mean speed and direction for scatterometer-derived ocean winds (a to d) and currents (e to g) in the region of Cape Verde, between the years of 2003-2014. Seasons are grouped as follows: Winter (December; January and February); Spring (March; April; May); Summer (June; July and August); Autumn (September; October; November). Wind data: QuikSCAT and ASCAT; Current data: GlobCurrent V2.0 Total 15m.

\section{Data acquisition and processing}

\subsection{Eddy detection and tracking}

Given the fact that mesoscale eddies have distinctive characteristics that can be used for this purpose - such as Sea Surface Temperature (SST) anomalies (Caldeira ${ }_{325}$ et al., 2002, 2014; Sangrà et al., 2005; Dong et al., 2009), surface roughness signature (Fu \& Holt, 1983; Yamaguchi \& Kawamura, 2009; Karimova, 2012), enhanced levels of primary productivity (Arístegui et al., 1994; Basterretxea et al., 2002; Pullen et al., 2008) and sea surface elevation/depressions (Holland \& Mitchum, 2001; Chaigneau ${ }^{33}$ et al., 2009; Chelton et al., 2011) - one may arrive to the false assumption that autonomous methods for eddy detection and tracking are easily achieved. The fact is that only altimetry can provide a regular and reliable monitoring capability, since it performs well regardless of cloud $^{335}$ cover and oceanic conditions (Robinson, 2010). Nonetheless, altimetry-based tools are susceptible to errors since they depend on: (1) the limited spatio-temporal availability of the satellite tracks (Sangrà et al., 2009; Ioannou et al., 2017; Le $\mathrm{Vu}$ et al., 2018); (2) the coarse resolu- ${ }^{340}$ tion of $1 / 4^{\circ}$ of the currently available gridded products;
(3) the limitation on data interpolation near land (Sangrà 320 et al., 2009); (4) only surface information (from threedimensional structures) can be retrieved (Faghmous et al., 2015). Albeit only providing reliable data on mesoscale features and processes, altimetry-based tools have evolved in recent years and are now in better agreement with empirical observations.

In this study we use the the Angular Momentum Eddy Detection and tracking Algorithm (AMEDA, Le Vu et al., 2018) which combines the physical parameters and geometrical properties of the velocity field. Due to the limited resolution of altimetry products, the combination of several datasets was reported to improve the capacity for detecting mesoscale features, especially eddies (Pascual et al., 2006). Thus, the algorithm is run with the multimission altimeter satellite gridded maps for Absolute Dynamic Topography (ADT) and geostrophic velocity fields, produced and distributed by the Copernicus Marine and Environment Monitoring Service (CMEMS). Although most eddy detection methods are based on Sea Level Anomaly (SLA) fields that represent the variable part of the Sea Surface Height (SSH), ADT serves a better purpose for it incorporates the variable and constant part of the SSH av- 
eraged over a 20-year reference period (Le Vu et al., 2018). AMEDA's biggest advantages are related with the dependence on few tunable parameters and, besides providing reiable information on the dynamical properties, it provides additional information on merging and splitting events, a recurrent phenomenon in an eddying environment such as Cape Verde region (Schütte et al., 2016a). The algorithm identifies an eddy by detecting an extreme of Local Norrameter which is maximum at the centre of the swirling motion and thus intrinsic to all eddies, first introduced by Mkhinini et al. (2014). Their shapes are then computed, based on the mean velocity for each SSH contour $(0.2 \mathrm{~cm})$ expected to increase towards the perimeter until a maximum circum-average geostrophic speed $\left(V_{\max }\right)$ is reached. This marks the primary delimitation and radius $\left(R_{\max }\right)$ of the eddy. Subsequently the velocity profile decreases until the last closed contour ( $V_{\text {end }}$ and $R_{\text {end }}$ ) is reached. Throughout this study $V_{\max }$ and $R_{\max }$ are used to quantify the kinematic properties of the eddies. The third step of the algorithm is the tracking procedure, based on the "Local Nearest Neighbour" methodology which associates sign in timestep $t+1$. The search area is based on the theoretical distance an eddy can travel in one day. For this study a $6.5 \mathrm{~km} \mathrm{~d}^{-1}$ propagation speed is set, based on the estimated mean westward propagation speed for eddies in latitudes comprising Cape Verde, which in turn is very close to the local mean westward phase speeds of long baroclinic Rossby waves (Chelton et al., 2011). When several eddies are detected within the search area a global cost function is used, taking into account the distance, radius and the normalised relative vorticity (vortex Rossby number) between eddies at $t 0$ and $t+1$.

AMEDA is also capable of searching for lost tracks for a user-specified number of time-steps. This is a big advantage when using altimetric data because an eddy may disappear between consecutive maps if the satellite tracks do not cross the structure for several days (Sangrà et al., 2009; Schütte et al., 2016a; Chaigneau et al., 2008) and may lead to the false identification of lost eddies as new. Considering that the susceptibility to error in associating supposedly terminated eddies to interpolated tracks increases with the number of associated time-steps (Faghmous et al., 2015), a 10-day interval is used. Finally, the last step is the identification of merging and splitting events, a novel approach in autonomous eddy tracking tools. This is an extremely valuable information for assessing the dynamical evolution of eddies and for the determination of water masses within eddies. Subsequently several eddy parameters are calculated. To quantify the eddy's intensity relative to earth's rotation rate, the vortex Rossby number (also known as normalised relative vorticity) is calculated with the equation:

$$
R o=\zeta / f
$$

where $\zeta$ and $f$ represent the vortex relative vorticity and the local Coriolis parameter, respectively. To assess the efficiency of an eddy to trap water in its interior the nonlinearity parameter is calculated, in which by the metric:

$$
\text { Nonlinearity }=V_{\max } / c
$$

$V_{\max }$ is the maximum circum-average geostrophic current speed and $c$ is the respective translation speed (Chelton et al., 2011). For a better visualisation and interpretation of background and island-induced eddies (Fig. 9 and 13, respectively), ADT maps were normalized by rescaling the data:

$$
\begin{aligned}
A D T_{\text {norm }}= & \frac{A D T-A D T_{\min }}{A D T_{\max }-A D T_{\min }} \\
& \times\left[n e w_{\max }-n e w_{\min }\right]+n e w_{\min }
\end{aligned}
$$

where $n e w_{\min }=-20$ and $n e w_{\max }=20$.

\subsection{Wind}

Wind speed and direction is provided by the QuikSCAT Level 2B V3.1 and ASCAT V2.1 datasets. These products rely on scatterometer-based technology that emits microwave pulses to measure the ocean surface roughness, which is highly correlated with the near-surface $(10 \mathrm{~m})$ wind field (Chavanne et al., 2002; Hoffman \& Leidner, 2005). The usage of an active sensor implies that data can be retrieved under all weather and cloud conditions, despite some limitations associated with rain contaminations and high wind speed measurements. The QuikSCAT dataset was produced by NASA/Jet Propulsion Laboratory and distributed by the NASA Physical Oceanography Distributed Active Archive Center (PO.DAAC). The satellite had a recurrent period of approximately $\approx 4$ days and collected data on a $1800 \mathrm{~km}$-wide band. The combination of the orbital period (14.25 orbits d $\mathrm{d}^{-1}$ ) and inclination $\left(98.62^{\circ}\right)$ resulted in a $90 \%$ daily coverage of the global ice-free ocean (Moroni et al., 2013). Although it exceeded its operational time expectancy, QuikSCAT data is only available from July 1999 to November 2009. For the remaining period of our study, ASCAT data is used. It was produced by EUMETSAT and reprocessed by the Remote Sensing System organisation. It underwent a reprocessing procedure by applying the new C-2015 Geophysical Model Function (GMF), based on the Ku-2011 GMF (QuikSCAT) which was subjected to significant improvements, tackling issues such as rain contaminations, sampling limitations and ambiguous direction retrievals (Fore et al., 2014). Thus, ASCAT is now in better agreement with QuikSCAT (Ricciardulli, 2016), being the best option to fulfil the purpose of the current study. Both datasets are available at a $12.5-\mathrm{km}$ spatial resolution. Data was projected into a spatially uniform grid and averaged over 8 days prior to the respective day in order to minimize the gaps created by the satellite tracks. The wind-stress 
$\left(\tau_{\text {wind }}\right)$ is calculated based on Gill (1982):

$$
\tau_{\text {wind }}=\rho_{\text {air }} C_{D} W^{2}
$$

where $\rho_{\text {air }}$ is the density of the air $\left(1.2 \mathrm{~kg} \mathrm{~m}^{-3}\right), C_{D}$ is the non-linear wind-drag coefficient - based on Large \& Pond (1981), modified for low wind speeds (Trenberth et al., $1990)$ - and $W$ is the wind speed 10-m above sea surface. The wind-stress curl was calculated with the following equation:

$$
\nabla \times \tau_{w i n d}=\frac{\partial \tau_{v}}{\partial_{x}}-\frac{\partial \tau_{u}}{\partial_{y}}
$$

where $\tau_{u}$ and $\tau_{v}$ are the zonal and meridional wind-stress components, respectively. With the main purpose of quantifying the island-induced wind disturbances on transiting background and island-induced eddies, Ekman pumping ${ }^{405}$ velocities $\left(\omega_{E k T}\right)$ were calculated following Stern (1965):

$$
\omega_{E k T}=\omega_{E k L}+\omega_{E k N L}
$$

The linear term $\left(\omega_{E k L}\right)$ estimates the vertical velocity based on the divergence/convergence of the Ekman transport provoked by the wind-stress curl:

$$
\omega_{E k L}=\frac{1}{\rho_{o}(f+\zeta)}\left[\frac{\partial \tau_{\mathbf{v}}}{\partial_{x}}-\frac{\partial \tau_{\mathbf{u}}}{\partial_{y}}\right]
$$

where $\rho_{o}=1026 \mathrm{~kg} \mathrm{~m}^{-3}$ is the sea water density and $\zeta$ is the relative vorticity given by $\zeta=\partial_{x} v_{g}-\partial_{y} u_{g}$, where $v_{g}$ and $u_{g}$ are the gesotrophic current components. The ${ }^{415}$ nonlinear term $\left(\omega_{E k N L}\right)$ on the other hand assesses the advection of surface relative geostrophic vorticity by the wind-forced Ekman transport in the mixed layer:

$$
\omega_{E k N L}=\frac{1}{\rho_{o}(f+\zeta)^{2}}\left[\tau_{\mathbf{v}} \frac{\partial(\zeta+f)}{\partial_{x}}-\tau_{\mathbf{u}} \frac{\partial(\zeta+f)}{\partial_{y}}\right]
$$

and depends largely on the net vorticity of the flow $(\zeta+f)$ (Mahadevan et al., 2008). For both linear an nonlinear terms the wind-stress computation is modified to account for the eddy-wind interaction:

$$
\begin{gathered}
\tau_{\mathbf{u}}=\rho_{a i r} C_{D}\left(u_{r e l}\right)\left|u_{r e l}\right| \\
\tau_{\mathbf{v}}=\rho_{a i r} C_{D}\left(v_{r e l}\right)\left|v_{r e l}\right|
\end{gathered}
$$

in which the relative velocity components $u_{r e l}=u_{w i n d}-u_{g}$ and $v_{r e l}=v_{\text {wind }}-v_{g}$, where $u_{\text {wind }}$ and $v_{\text {wind }}$ are the wind speed components. One should note that the effec- ${ }^{430}$ tive wind-stress is larger when the wind and geostrophic speed components are in opposing directions (Allis, 2015).

\subsection{Chlorophyll a}

In the interest of determining the biological impact of background and island-induced eddies, daily Chl $a$ satellite observations with a $4.63-\mathrm{km}$ spatial resolution were retrieved from the "OceanColor" website (https : //oceandata.
sci.gsfc.nasa.gov/MODIS-Aqua/Mapped/). Chl $a$ is the most important pigment in the respiration process of phytoplankton. It absorbs mostly blue light and reflects the green, resulting in a ratio that can be used as a proxy for determining Chl $a$ concentrations at the ocean surface (Robinson, 2010; Andrade et al., 2014; Caldeira et al., 2002; Andrade et al., 2014). Nevertheless, the presence of aerosols/dust load in the atmosphere and suspended sediments at the ocean surface may lead to Chl $a$ overestimation (Helmke et al., 2005; Tilstone et al., 2011). This dataset was recorded by the Moderate Resolution Imaging Spectroradiometer (MODIS) instrument flying aboard NASA's Aqua satellite. It has a viewing swath width of $\approx 2330 \mathrm{~km}$ in a sun synchronous polar orbit, providing an almost complete global coverage in 1 day (Savtchenko et al., 2004). Due to the frequent cloudy conditions provoked by the seasonal positioning of the ITCZ (Fernandes et al., 2000; Karstensen et al., 2015), an 8-day centered moving average was computed to avoid large gaps in data.

\section{Results and discussion}

The findings of the present study are presented and discussed below. The spatiotemporal heterogeneity of altimetric swaths can induce spurious eddy detections (Ioannou et al., 2017; Le Vu et al., 2018). Thus, it is very important to filter the spurious from the most relevant eddies and still have a sufficiently large population to execute a robust qualitative and statistical characterisation. Eddies with a lifetime $<10$ days are eliminated from the dataset but only long-lived eddies - with a lifetime $\geq 60$ days are considered throughout the study. For the investigation of seasonal patterns, seasons were grouped as follows: (a) Winter: December, January and February; (b) Spring: March, April and May; (c) Summer: June, July and August; (d) Autumn: September, October and November.

\subsection{Eddy hotspots and pathways}

The identification and characterisation of the predominant eddy birthplaces and pathways is important for several reasons: (1) it helps to determine the main geographical patterns and generation mechanisms; (2) gives valuable information about the average lifetime and propagation expectancy of eddies being generated at a certain location; (3) it can give us clues about the possible biogeochemical properties of the water being advected within them.

Fig. 5 shows the number of eddies being generated in every $1^{\circ}$ area between the years of 2003-2014, filtered by minimum lifetime. Coastal areas have been largely associated with mesoscale variability (Chelton et al., 2011), especially when characterised by an upwelling system (Barton et al., 1998; Chaigneau et al., 2008). Naturally, the northwest African coast is no exception. Several hotspots are perceivable when accounting for all eddies (Fig. 5a), 
${ }_{440}$ particularly in Cape Blanc (56-85 per bin), Cape Vert (36$47)$ and in the south-easternmost limit of the study area (95). Most of the bins within $\mathrm{CV}$ area have a record that 480 range between 21-57 eddy detections, which is significant but still not far from the surrounding area. As the lifetime

445 threshold increases to 30,60 and 90 days (Fig. 5b, c and $\mathrm{d}$, respectively), the number of eddies originating within $\mathrm{CV}$ area (in relation with its surroundings) also increases 485 significantly.

By contrast, the African coast loses much of its signifi450 cance, especially in the southernmost part. Cape Blanc is the main eddy hotspot for every threshold. This location is characterised by intense along-slope flow convergence, ${ }^{490}$ often linked to the generation of giant filaments and eddies that promote the transport of cold, nutrient-rich up455 welled water to offshore (Van Camp et al., 1991; Gabric et al., 1993; Pelegrí et al., 2006; Nieto et al., 2012; Fischer et al., 2009)). Similarly, Schütte et al. (2016a) detected ${ }_{495}$ the generation of at least 50 eddies (lifetime $\geq 7$ days and 45-km radius) between 1995 and 2013 in Cape Blanc.

460 Current results further confirm the hypothesis of a small eddy corridor first introduced by Sangrà et al. (2009). Another hotspots for long-lived eddies are perceivable near 500 the Mauritanian coast and the Cape Vert headland (Fig. $5 \mathrm{c})$. Considering that eddy propagation is directly proportional to the eddy lifetime, there is a good probability that these eddies can intersect Cape Verde islands.

Regarding the island-induced, several eddy hotspots are ${ }^{505}$ well distinct in the lee of the westernmost islands. The windward group is the dominant hotspot for all lifetime thresholds, generating approximately 12, 4 and 5 more eddies than the leeward group for a minimum lifespan of 10,30 and 90 days, respectively. The location of these ${ }^{510}$ hotspots is very intriguing because they appear in the immediate vicinity of Fogo and Santo Antão islands, the highest of the archipelago with 2829 and 1979 meters altitude, respectively (Fig. 2). The latter is also in good agreement with Schütte et al. (2016a), who recognized these ${ }^{515}$ areas as the most prominent eddy hotspots away from the African coast. As previously introduced, deep-ocean islands can trigger the generation of eddies through atmospheric and oceanic processes. These have been subject of intense studies in other islands, mainly in the Hawaii (e.g. Calil et al., 2008; Yoshida et al., 2010; Jia et al., 2011), Canary Islands (e.g. Arístegui et al., 1994; Sangrà et al., 2007; Jiménez et al., 2008) and Madeira (e.g. Couvelard et al., 2012; Caldeira et al., 2014, 2002). Cape Verde shares remarkable similarities with these islands, in the sense that all are characterised by high mountains - well above the lower atmospheric inversion layer (Chavanne et al., 2002; Hafner \& Xie, 2003; Caldeira \& Tomé, 2013; Barton et al., 2000) - and are exposed to constant trade winds (Fig. 4 upper panels). Thus, current results are somewhat expected.

The calculation of the geostrophic Eddy Kinetic Energy $\left(E K E=\frac{1}{2}\left[u^{2}+v^{2}\right]\right)$ is a very useful parameter mainly because it represents the energy induced by vortices in the environment. However, only the frequency and intensity of such features can be traced, being thus unable to discriminate eddy hotspots from pathways. For this reason, the seasonal number of long-lived eddy origins in combination with EKE maps are shown in Fig. 6 upper and lower panels, respectively. The region of Cape blanc is marked by high EKE values throughout the year $\left(\approx 450 \mathrm{~cm}^{2} \mathrm{~s}^{-2}\right)$, which is in perfect agreement with the seasonal long-lived eddy origins (7-12). The southernmost coastal area between $10-13^{\circ} \mathrm{N}$ is also highlighted all year round, but this signal is related to the short-lived eddy signals identified in Fig. 6a and does not appear in the seasonal long-lived eddy origins (Fig. 6 upper panels). At the African coast between Cape Vert and Cape Blanc the EKE signal is lowest during winter and spring (Fig. 6e and f), concurrently to the southernmost extension of the upwelling system (Van Camp et al., 1991; Nykjær \& Van Camp, 1994; Lázaro et al., 2005). During summer, EKE increases significantly in this region $\left(300-\approx 350 \mathrm{~cm}^{2} \mathrm{~s}^{-2}\right)$, merging the Cape Blanc branch at higher latitudes (Fig. 6g). This

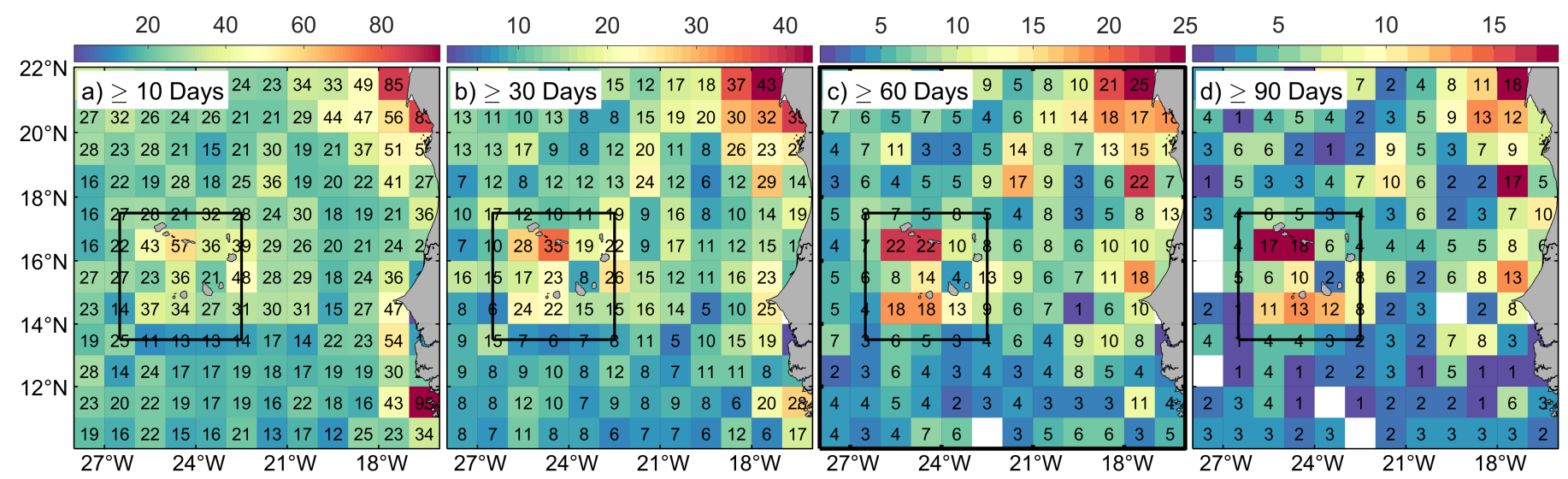

Figure 5: Geographical distribution of the number of eddies generated in every $1^{\circ}$ bin between $2003-2014$, filtered per lifetime threshold. Black thick lines represent the CV area. 


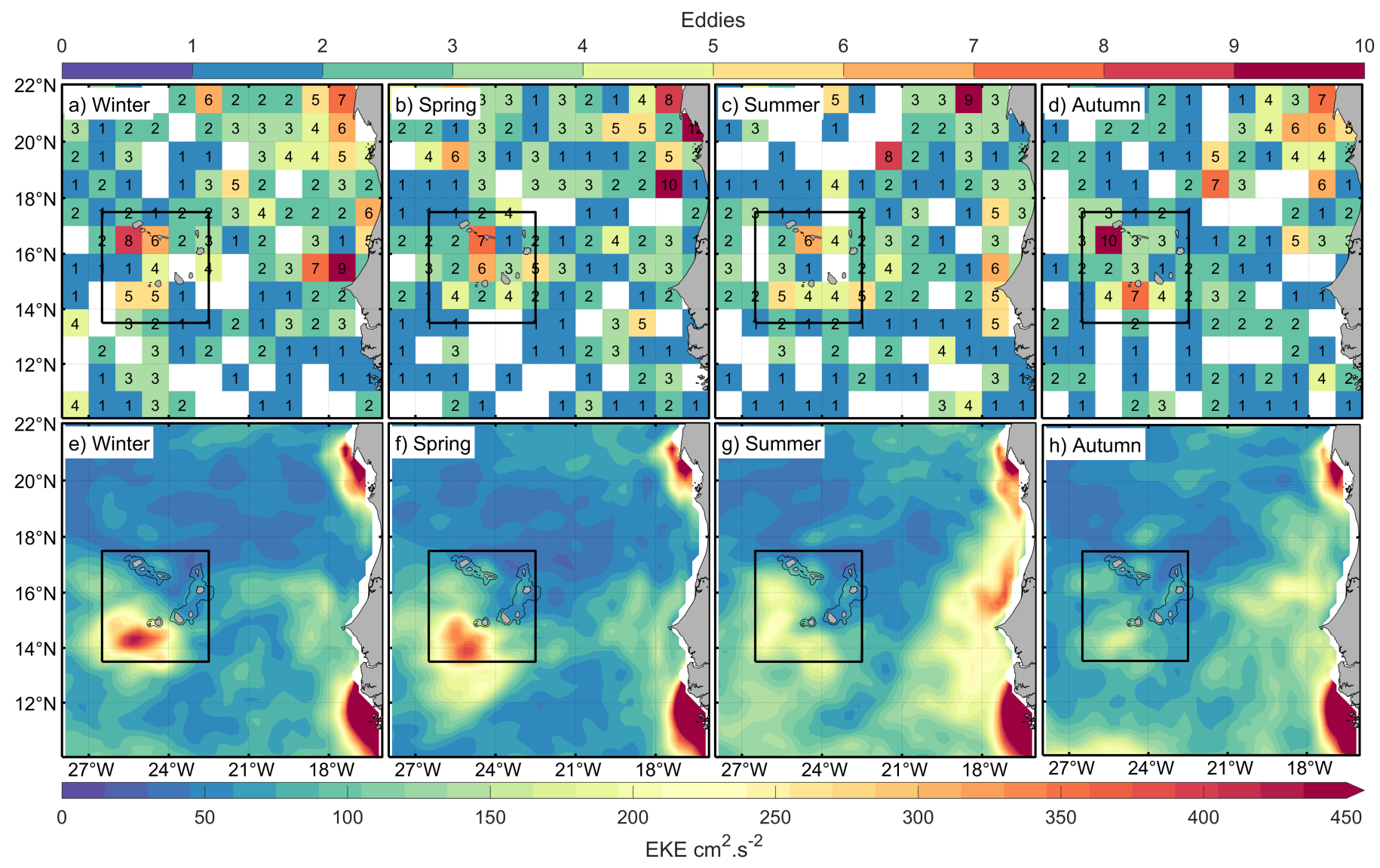

Figure 6: Seasonal number of long-lived ( $\geq 60$ days) eddy origins per $1^{\circ}$ bin (a to d) and mean EKE (2003-2014) calculated from ADT-derived geostrophic current components. Solid black line represents CV area and thin black contour around the islands represents the $-2000 \mathrm{~m}$ bathymetry.

happens concurrently to the maximum intensification and extension of the Mauritanian Current (MC; Mittelstaedt, 1991; Lázaro et al., 2005).

Schütte et al. (2016a) strongly associated MC to the formation of eddies that propagate westward in the direc- ${ }^{545}$ tion of Cape Verde. These authors also designated this season as the period of maximum eddy generation at the coast and linked the eddy generation mechanisms to the dynamic instabilities of MC. Nonetheless, the highest number of long-lived eddies originating in $1^{\circ}$ coastal bin does ${ }^{550}$ not exceed 5 in summer (Fig. 6c), which is possibly related to the merging with other eddies before the 60-day minimum lifespan.

An interesting EKE trail starting in the immediate vicinity of the Cape Vert headland is depicted for all seasons. It is more pronounced during summer $\left(\approx 350 \mathrm{~cm}^{2} \mathrm{~s}^{-2}\right.$, Fig. $6 \mathrm{~g})$ but reaches its highest extension during winter, spring and autumn (Fig. 6e and h, respectively). Though less obvious but always perceivable, this area can be defined as a hotspot for long-lived eddies (Fig. 5c) that are more ${ }^{560}$ often generated during winter and summer (Fig. 6a and c, respectively). Schütte et al. (2016a) documented the generation of a substantial number of eddies near the Cape the areas north and south/southwest of the headland, respectively. Alpers et al. (2013) also documented the formation and evolution of a sub-mesoscale cyclonic eddy (not detectable on altimetry sensors) generated in autumn by the headland's topographic effects on a sudden increase of the trade winds. This eddy transported upwelled nutrientrich water through approximately $200-\mathrm{km}$ offshore, causing a phytoplankton bloom until it disintegrated 31 days after its generation. From past and current findings it is therefore reasonable to expect that many far-field eddies originated here may reach the archipelago.

Regarding the island-induced, the westernmost leeward islands are marked by a high EKE signal perfectly depicted in all seasons, reaching maximum intensity $\left(\approx 450 \mathrm{~cm}^{2} \mathrm{~s}^{-2}\right)$ and extension during winter and spring, respectively (Fig. $6 \mathrm{e}$ and $\mathrm{f}$ ). These conspicuous EKE seasonal signals could be evidence of an eddy generation signature, but this is contradictory to the long-lived eddy seasonal origins which show only 10 and 6 detections in this region during winter and spring, respectively (Fig. 6a and b). Since approximately half of the eddies generated in the leeward wake are long-lived (Fig. 5a and c), this unconformity between eddy origins and EKE may be explained by a long residence time that prevents the generation of new eddies. In 
${ }_{565}$ fact, Lázaro et al. (2005) linked the presence of high EKE values in the lee of Fogo to a nearly permanent anticyclonic eddy which reached maximum speeds in spring. More re-620 cently, García-Weil et al. (2014) observed a remarkable 16-year average EKE signal in the same location while de-

570 scribing the mesoscale dynamics in the Canary Islands. Nonetheless, the possible island-induced intensification of transiting background eddies cannot be neglected, consid-625 ering the previously referred EKE trail that extends from the Cape Vert promontory to the archipelago in winter 575 and spring (Fig. 6e and f, respectively).

Summer is the season with lowest near-field eddy generation records (Fig. 6c) but the EKE field is still per- ${ }^{630}$ ceivable, contouring very closely the islands bathymetry with maximum values of $\approx 220 \mathrm{~cm}^{2} \mathrm{~s}^{-2}$ (Fig. 6g). Au-

580 tumn is the season with lowest EKE values, reaching a maximum of $\approx 170 \mathrm{~cm}^{2} \mathrm{~s}^{-2}$ southwest of Fogo (Fig. $6 \mathrm{~h}$ ). Nonetheless, this season is marked by the generation of 13 and 11 long-lived eddies in the windward and leeward islands, respectively (Fig. 6d). The seasonal variation of the near-field EKE follows a similar behaviour as the wind, which reaches highest speeds from December to May and decreases significantly in the remaining months (Fig. $4_{640}$ upper panels; DGA, 2004).

\subsection{Exposure to background incoming eddies}

Coastal-generated eddies are subjected to many pro-645 cesses in their transition to offshore. The hydrographic and biogeochemical properties of some of these features were the focus of recent studies (Fischer et al., 2016; Fiedler et al., 2016; Hauss et al., 2016; Karstensen et al., 2015; Löscher et al., 2015; Schütte et al., 2016a,b; Romero et al. ${ }^{65}$ 2016), yet their interaction with the Cape Verde Archipelago has received no attention to present date. To the best of our knowledge, most studies concerning eddy-island interaction were conducted under laboratory (e.g. Cenedese, 2002; Adduce \& Cenedese, 2004; Cenedese, 2005; Tanabe ${ }^{65}$ \& Cenedese, 2008; Andres \& Cenedese, 2013) and model experiments (e.g. Simmons \& Nof, 2000, 2002; Stern, 2000). Empirical case studies are extremely rare (e.g. Chang et al., 2012) and as Yang et al. (2017) suggested, further investigations must be conducted to systematically describe and ${ }^{660}$ comprehend such phenomenon.

Long-lived background eddy trajectories and places of origin are represented in Fig. 7a and b, accounting for approximately $69 \%(80 / 116)$ and $54 \%(53 / 98)$ of the total cyclonic and anticyclonic background eddies, respectively. ${ }^{665}$ From a total of 133, 107 interact directly with the $-2000 \mathrm{~m}$ bathymetry and although 29\% (38/133) do not intersect the islands, these can still be influenced by island-induced processes especially in the southern $\mathrm{CV}$ area where the wind wake extends for $\approx 200 \mathrm{~km}$ (Fig. $4 \mathrm{a}$ and b). All ${ }^{670}$ background eddies travel westward with some meridional deflections along the way (Fig. 7a). At latitudes between $15-17^{\circ} \mathrm{N}$ the archipelago appears to act as an extremely effective barrier to incoming eddies, creating a shadow effect west of the islands where very few eddy trajectories are observed. This spatial pattern was also observed by Schütte et al. (2016a), where anticyclonic and cyclonic eddies originated in the coast formed distinct corridors as they propagated westward, leaving a void in the immediate vicinity of the Cape Verde Archipelago. As mentioned before, the archipelago is constituted by 2 main chains of islands with relatively shallow depths between them, especially between Boa Vista and Maio (Fig. 2; Ramalho, 2011). Considering that the vertical structure of local eddies were reported to extend up to $\approx 1400 \mathrm{~m}$ in depth (Karstensen et al., 2015), bathymetry effects are very likely to block and deflect their propagation, or even induce drag and consequent dissipation of such features. Furthermore, some background eddies can still undergo through transformation processes, giving rise to new eddies in the opposite side through splitting or merging events.

The easternmost islands are the most impacted by background eddies, especially anticyclonic (Fig. 7a). The ones that form closest to the African coast are agglomerated near the Cape Vert headland (Fig. 7b), previously designated as a background eddy hotspot (Fig. 5) and pathway (Fig. 6). From these eddies, cyclonic tend to intersect the easternmost islands while anticyclonic are mostly deflected southwestard, being partly responsible for the distinct background anticyclonic eddy corridor observed in the lee of the leeward islands. Fogo is the island less affected by background eddies as it seems to be sheltered by Santiago and Maio islands. The windward group is intersected almost exclusively by cyclonic eddies that contour very closely the northern chain as they propagate westward. The majority of these eddies originate between 16$19^{\circ} \mathrm{N}$ and around $20^{\circ} \mathrm{W}$. A small area with no tracks is also depicted in the north of Sal ( $7 \mathrm{a}$ and $\mathrm{c}$ ). This behaviour is expected to occur in the presence of an obstacle (e.g. seamount, Yang et al., 2017), but there is no topographic structure that can explain this. Only one background eddy originates near Cape Blanc. Albeit being an eddy hotspot depicted for all lifetime thresholds (Fig. 5), it is highly unlikely that eddies created at this location can intersect the islands, since they need to deflect $\approx 300 \mathrm{~km}$ southward in a relatively short distance to be considered as such.

From the visual analysis of the sequential ADT maps and background eddy trajectories it was possible to determine that: 22 managed to propagate through $\mathrm{CV}$ area with no significant implications; 58 were deflected either by the islands bathymetry or by the interaction with islandinduced eddies or wind-shear effects; 27 resulted in eddy splitting induced by the islands bathymetry, giving rise to new near-field eddies; 39 merged either with their offspring or with island-induced eddies; 12 were intensified by island-induced wind-shear effects; and 31 were destructed when interacting with the islands bathymetry or with island-induced eddies. Is is important to note that many 


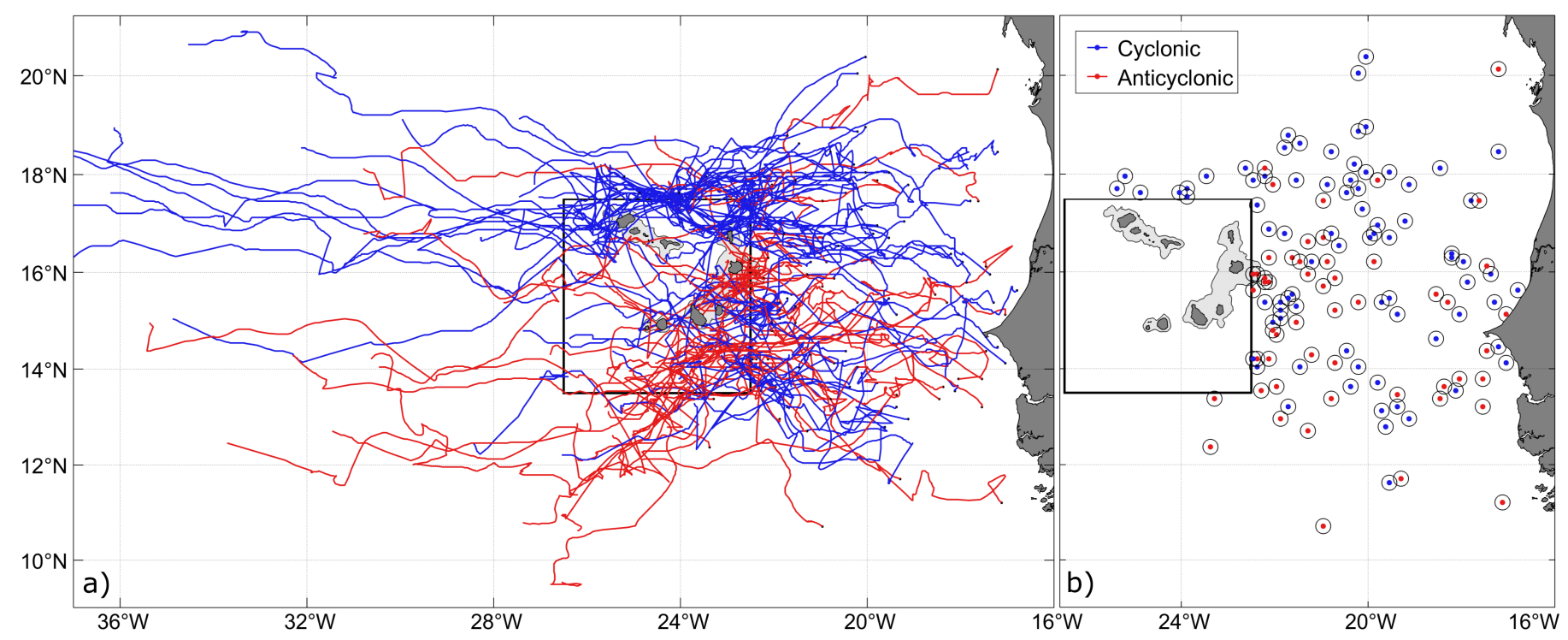

Figure 7: Background long-lived ( $\geq 60$ days) eddy trajectories (a) and points of origin (b). Longest eddy propagates up to $\approx 47^{\circ} \mathrm{W}$.

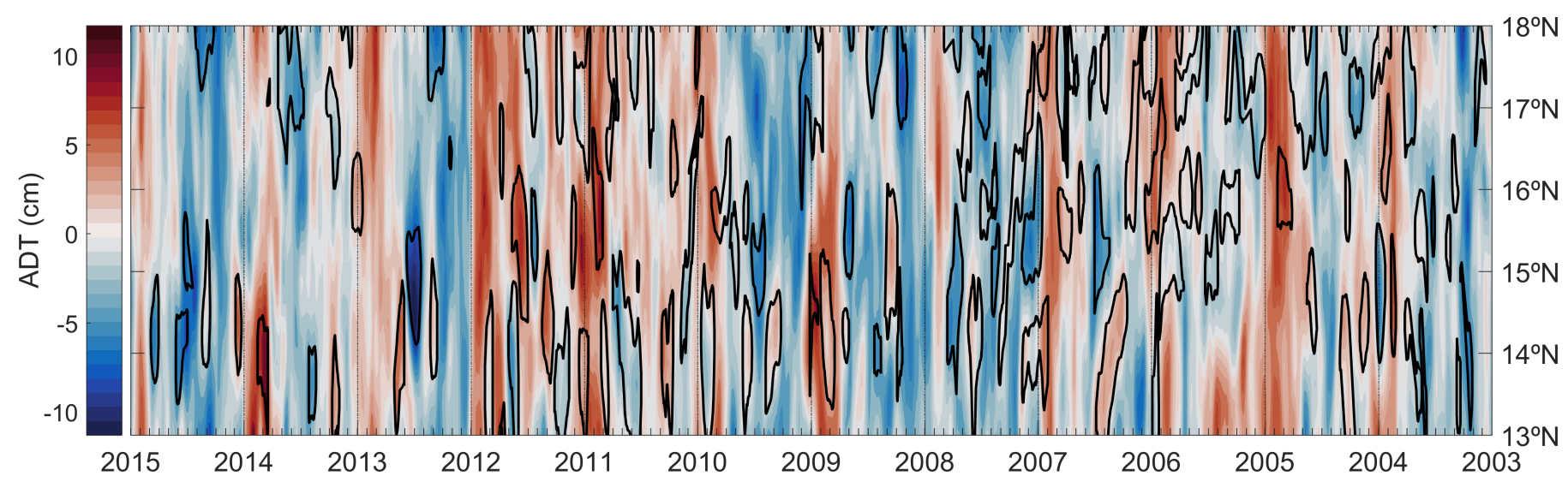

Figure 8: Zonal Hovmöller diagram for ADT along $22.5^{\circ} \mathrm{W}$ and latitudes from $13-18^{\circ} \mathrm{N}$. Black contours represent the perimeter of long-lived incoming eddies intersecting the cross-section. The horizontal axis is inverted to simulate the westward eddy propagation in time.

background eddies experienced multiple outcomes, such as merging events often provoked by their deflection when interacting with the islands bathymetry.

For the determination of seasonal patterns in the background eddy intersection with the archipelago, an ADTbased Hovmöller diagram is presented in Fig. 8, using a meridional cross-section set at the eastern CV boundary $\left(22.5^{\circ} \mathrm{W}\right)$. Although some eddies approach the archipelago ${ }^{700}$ from the north and from the south, most of them come from the east (Fig. 7), thus the positioning of the cross section and the orientation of the horizontal axis. After the determination of a $3.77 \mathrm{~mm} \mathrm{yr}^{-1}$ mean linear trend in the ADT at the cross-section, which is in good agreement ${ }^{705}$ with Church \& White (2011) calculations for the region, a linear least squares detrending was performed to avoid biased interpretations. Positive (anticyclonic) and negative (cyclonic) normalised ADT signals are more frequent in the lower and upper half of the Hovmöller, respectively, following the same pattern depicted in Fig. 7a. Eddies are well distributed throughout the years, though there are some periods with higher eddy frequency such as the years between 2010-2012. The determination of a seasonal pattern is hindered by the apparent random distribution in time. Although current results contradict Schütte et al. (2016a) - who stated that coastal eddies generated in June normally intersect the archipelago between boreal winter and spring - this is somewhat expected since an EKE signal with varying shape and intensity is observed to reach the islands from the east during all seasons (Fig. 6). Furthermore, most of the background eddies intersecting the archipelago are originated at some distance from the coast. Despite the general dominance of negative/positive ADT values in the initial/final months of all the years, eddy polarity does not show a seasonal pattern. 


\subsubsection{Background eddy-island interactions}

The period between $5^{\text {th }}$ September $2006-16^{\text {th }}$ March 2007 was selected for the characterisation of 20 eddy trajectories, represented in Fig. 9. Several other eddies are perceivable in the ADT maps, but only the most representative are identified as " $\mathrm{A}_{n}$ " and " $\mathrm{C}_{n}$ " for anticyclonic and cyclonic eddies, respectively. To complement this analysis, the genealogy of the selected eddies is represented in Fig. 10 for a clear visualisation of the relationships between them.

Several eddies are observed during their westward propagation in Fig. 9a, being most of them generated in the vicinity of Cape Vert headland (A1, A2, A3, C2 and C4).775 In this date $\mathrm{C} 2$ interacts and merges the newly generated C3 after being deflected by the easternmost island's bathymetry. Albeit merging events between eddies of the same sign and identical water densities are recurrent and occur naturally (Nof \& Simon, 1987), topographic effects780 on eddies can effectively modify their propagation still at some distance from the obstacle (Yang et al., 2017). Topographic effects can also lead to the weakening and consequent dissipation of eddies (Chang et al., 2012), as it is the case of the coastal-generated A3 (Fig. 9f).

A similar but contrasting effect appears to have been induced by the windward islands on C1's trajectory, contouring the islands until it splits and gives origin to C1.1 (Fig. 9a). It seems rather obvious that the splitting was prooked by the interaction with Santo Antão island, a phe-790 nomenon documented in the past for other islands Yang et al. (2017); Chang et al. (2012) and that results in the transfer of energy, momentum, salinity and temperature to the surrounding environment through small, dissipa-

740 tive scales Simmons \& Nof (2000); Cenedese (2005). After795 propagating in close proximity for $\approx 1$ month (Fig. 9b) the "parent" C1 and "child" C1.1 merged and became one coherent structure. In fact, this merging between "parents" and "offspring" is far from being an isolated case.

745 Following an identical pattern and ultimately the sameso fate, C3 approximates Santo Antão from the east (Fig. 9c) and decreases in size and propagation speed when intersecting the island (Fig. 9d), followed by the splitting and generation of another island-induced C3.1 again in the lee

750 of Santo Antão (Fig. 9e). The "parent" C3 and "child" 805 C3.1 merged precisely 1 month after splitting, replicating with extraordinary similarity the C1-C1.1 (Fig. 9b). The fact that such identical events occurred in such a short period ( $\approx 3$ months), in combination with the abundance of

755 cyclonic tracks observed in the northern side of the wind-810 ward islands (Fig. 7), gives us reasons to believe that this is a recurrent phenomenon and demonstrates that many island-induced eddies generated in the windward hotspots (Fig. 5c) may be directly related with background eddies.

760 The reason why the "parents" C1 and C3 merged with ${ }^{815}$ their "offspring" remains unclear. It has been demon- strated that island-induced wind-shear can effectively drive the generation and intensification of eddies in the lee of islands with high topography (e.g. Jiménez et al., 2008; Dickey et al., 2008; Jia et al., 2011; Caldeira et al., 2014; Piedeleu et al., 2009), but only recently these perturbations have been linked to the propagation of such features (Pullen et al., 2008; Couvelard et al., 2012). In order to better comprehend how the orographic-perturbed wind influences the interaction of background eddies with the islands, the 8-day averaged wind-stress curl is represented in Fig. 11, superimposed by the shapes and trajectories of some of the selected background eddies. Contrary to the C1-C1.1 case, which merge after propagating relatively close to each other (Fig. 9a and b), C3-C3.1 show a different behaviour as the "parent" and "child" are distant when they break but then deflect in the direction of each other and merge (Fig. 9e, f and g). Interestingly, a positive wind-stress curl band is depicted in the lee of Santo Antão when C3 splits (Fig. 11a), which then responds promptly to the wind burst and increases in area and intensity (Fig. 11b), driving C3.1 to concurrently increase its radius and rotational speed by $35.8 \mathrm{~km}$ and $\approx 0.06 \mathrm{~m} \mathrm{~s}^{-1}$, respectively, relative to the formation phase. It is possible that the orographic winds contributed to the meridional deflections of $\mathrm{C} 1$ and C1.1, favouring their interaction and merging.

Splitting events can still occur in the absence of topographic effects, as observed in A2 that originates the 370day-lived A2.1 at some distance from the nearest islands (Fig. 9c). Resembling the "parent-children" relationship of the previously described $\mathrm{C} 1-\mathrm{C} 1.1$ and $\mathrm{C} 3-\mathrm{C} 3.1, \mathrm{~A} 2$ and A2.1 merge in the subsequent snapshot (Fig. 9d) and form a quite impressive "family tree" (Fig. 10), for it involves two other anticyclonic eddies from very distinct origins. One of them is the coastal-generated A4 which propagates due west and merges A2.1, forcing the latter to invert its trajectory (Fig. 9f). A2.1 then recovers a westward propagation (Fig. $9 \mathrm{~g}$ and $\mathrm{h}$ ) and incorporates the island-induced A5 in the lee of Fogo (Fig. 9i and Fig. 11c).

Fig. 11a shows that the 73-day-lived island-induced A5 is most likely generated by the topographic blocking of the wind which in turn creates a negative wind-stress curl area in the eastern flank of the wake. This condition sets the stage for the spin-up of A5 that seems to be trapped by the presence of an island-induced cyclonic eddy (not identified) in the west (Fig. 9d to $\mathrm{g}$ and Fig. 11a and b). A5 is intensified under favourable wind-stress curl, reaching $\approx 0.20 \mathrm{~m} \mathrm{~s}^{-1}$ rotational speed and $41.6 \mathrm{~km}$ radius. Almost one month later (Fig. 11b) and still under the influence of favourable atmospheric conditions, A5 remains relatively stable with $\mathrm{a} \approx 58.6 \mathrm{~km}$ radius and $0.18 \mathrm{~m} \mathrm{~s}^{-1}$ rotational speed but at the time it merges with A2.1 (Fig. 9i), A5 is in an area of unfavourable positive wind-stress curl (Fig. 11c) - a condition that may well explain the significant decrease in radius $(21.9 \mathrm{~km})$ and rotational speed $\left(0.11 \mathrm{~m} \mathrm{~s}^{-1}\right)$. This case represents an interaction between a background and an island-induced eddy sustained by island-induced atmo- 

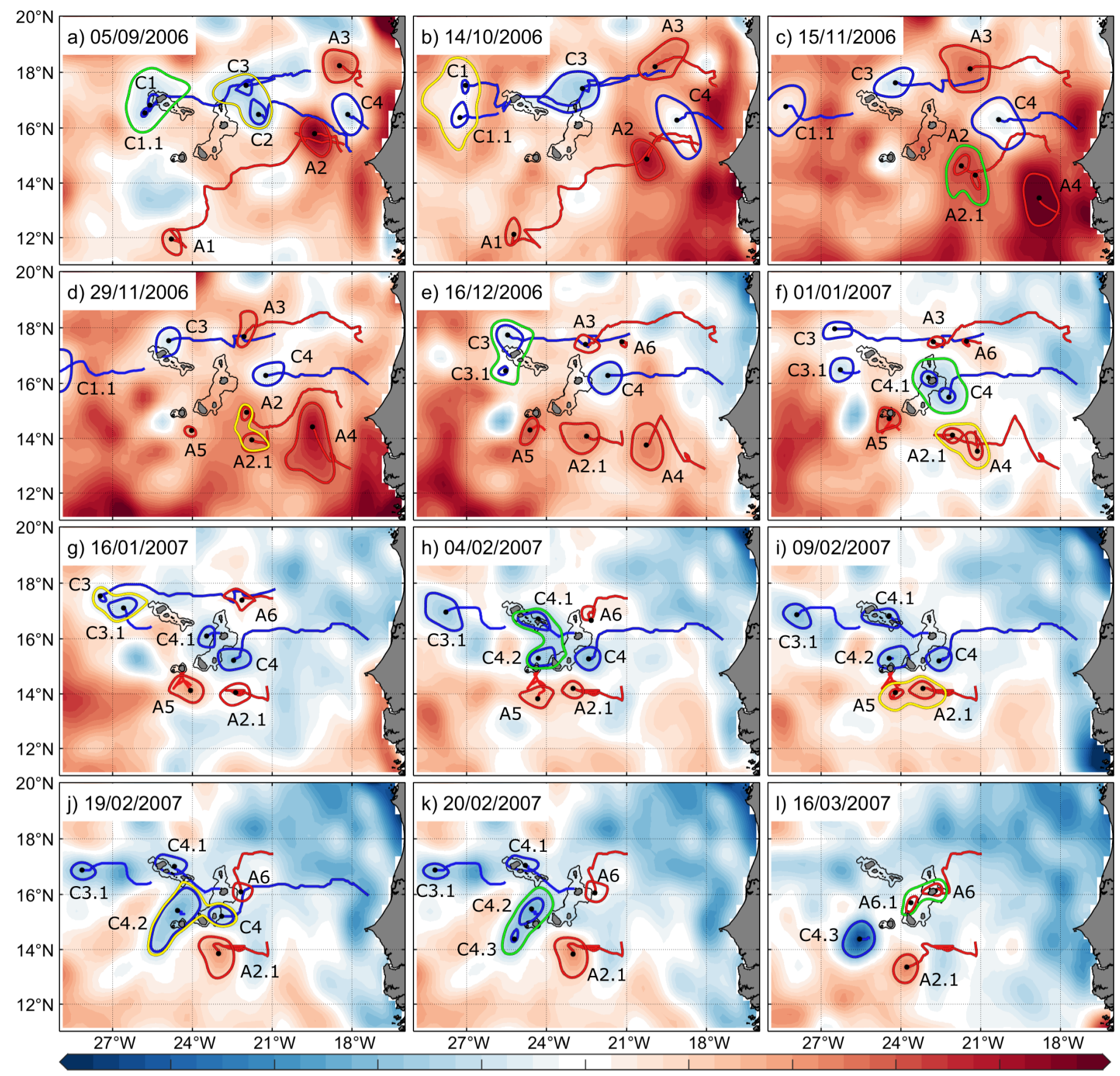

$-10$

$-8$

$-6$

$-2$

$\stackrel{0}{\text { ADT }_{\text {norm }}}$

Figure 9: Far-field eddies evolution snapshots from $30^{\text {th }}$ May 2006 to $2^{\text {nd }}$ May 2007, plotted against normalised ADT maps. Blue and red colours represent cyclonic and anticyclonic eddies, respectively. Green and yellow contours represent splitting and merging events, respectively. The thin black contour around the islands delimits the $-2000 \mathrm{~m}$ depth.

spheric processes, being therefore deemed as an indirect825 interaction with the islands.

After the merging event, A2.1 takes a south-westward trajectory (Fig. 9l), propagating through an area of negative wind-stress curl (Fig. 11e and f) which can effectively favour its coherence (Couvelard et al., 2012; Jia et al.,830 2011). This behaviour is also observed with A1 (Fig. 9a and b), although the latter can still benefit from the interaction with a nearby cyclonic eddy in the lee of Fogo. Such behaviour is suggested to occur when the interaction of two eddies of opposite sign results in the weaker one rotating around the stronger one (Kundu \& Cohen, 1990).

The most remarkable example of background eddy-island interactions is the case of $\mathrm{C} 4$, a coastal-generated eddy 


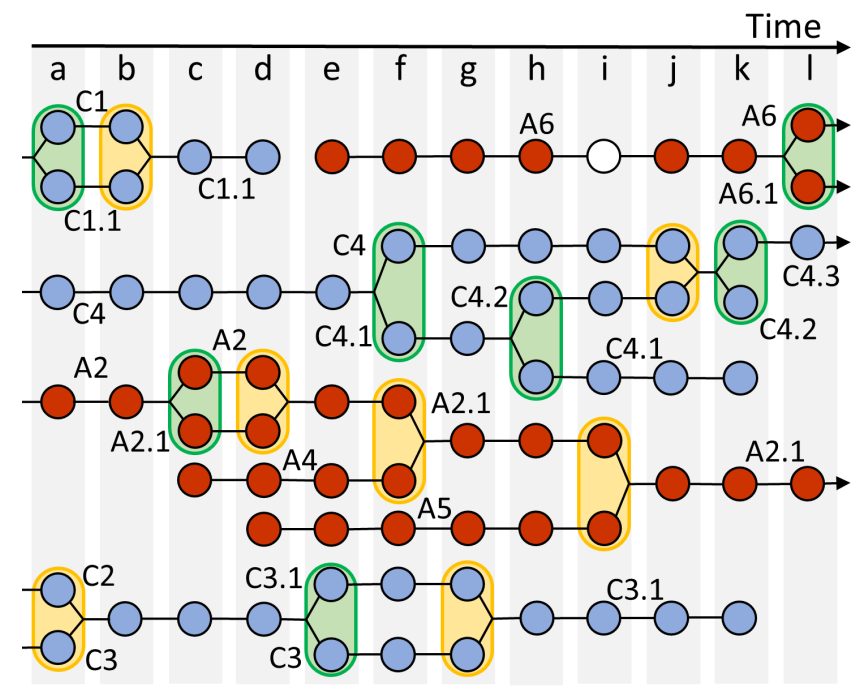

Figure 10: Eddy genealogy of the background specific eddy cases. Only those with interactions are represented. Empty circles represent missing eddy. The labels of each column are associated with the snapshots in Fig. 9. Green and yellow contours represent splitting and merging events, respectively.

that forms a highly complex "family tree" composed by 3 generations of island-induced eddies (Fig. 10). After propagating in the direction of the archipelago, C4's perimeter acts with Boa Vista (Fig. 11e) and deflects southward, increasing its radius from 63.6 to $108 \mathrm{~km}$ until it splits and forms the near-field $\mathrm{C} 4.1$ in the opposite side (Fig. 9f). Coincidently, this is the same location of the island-induced splitting of A6 (Fig. 91). As the "par-

ent's" C4 radius decreases to $\approx 30 \mathrm{~km}$, it remains stationary between Maio and Boavista while the "child" C4.1 propagates through the northern chain and splits, giving origin to $\mathrm{C} 4.2$ in the south (Fig. 9h). Struggling to go by the shallow channels between the easternmost islands

${ }_{845}$ (Fig. 9i), a streamer detaches from $\mathrm{C} 4$ and flows in a counter-clockwise direction along the northern side of the leeward islands, interacting and merging with its "grandchild" C4.2 (Fig. 9j).

This kind of streamers are governed by the conservation of circulation momentum around the islands (Andres \& Cenedese, 2013), which in turn results in a jet-like current in the island's passage and in the generation of other eddies of the same sign downstream (Cenedese, 2005). Considering that $\mathrm{C} 4$ remained stationary for 39 days while trying to overcome the islands, it is very likely that its persistence contributed to the formation of its "grandchild" C4.2.

Another streamer decouples from the elongated C4.2 and splits it in the following day, originating the 277day-lived "great-grandchild" C4.3 southwest of Fogo (Fig. $9 \mathrm{~m})$. Topographic effects must be one of the factors trig-875 gering this event, but Fig. 11c and d also reveal a conspicuous positive wind-stress curl signal at the western flank of the Fogo's wake, potentially favouring the south-westward growth and splitting of C4.2. This newly-generated A4.3 is

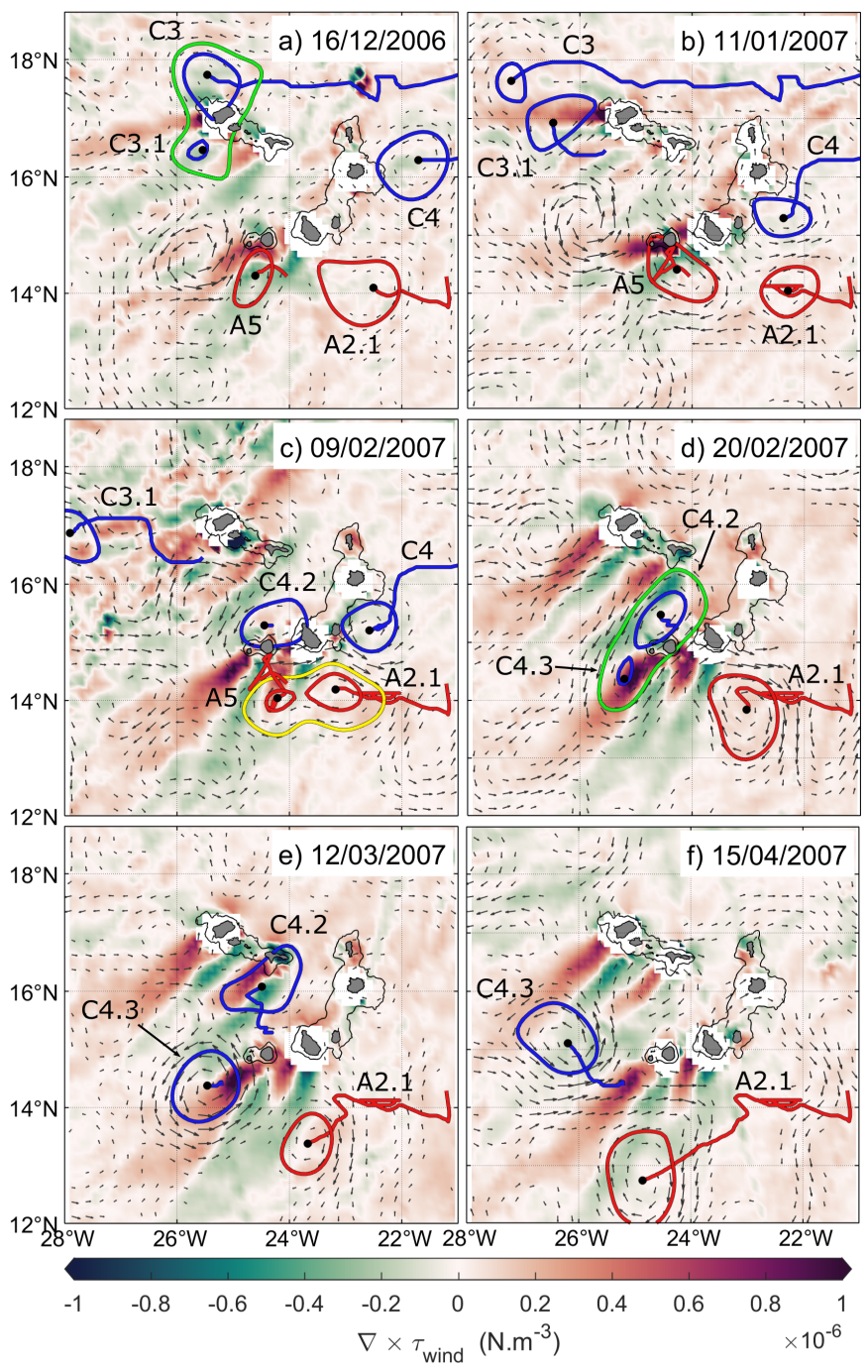

Figure 11: Specific cases of background eddies plotted against the wind-stress curl (8-day averaged prior to respective date). Blue and red colours represent cyclonic and anticyclonic eddies, respectively. Black arrows represent geostrophic current velocities $\left(\geq 0.8 \mathrm{~m} \mathrm{~s}^{-1}\right)$ from CMEMS.

later observed to spin at significantly high speeds $\left(0.43 \mathrm{~m} \mathrm{~s}^{-1}\right)$, very likely driven by the highly favourable island-induced wind-shear effects in the lee of Fogo (Fig. 11e).

\subsection{Island-induced eddies}

Besides the remarkable impact on incoming background eddies, it is expected that the Cape Verde islands can selfgenerate eddies, but the occurrence and generation mechanisms of such lens-shaped features have been seldom documented (Lázaro et al., 2005; Schütte et al., 2016a). Herein we focus our attention in the characterisation of long-lived island-induced eddies, represented in Fig. 12. From this selection, only $37 \%(91 / 243)$ and $32 \%(82 / 256)$ of the total cyclonic and anticyclonic island-induced eddies are being accounted for. 


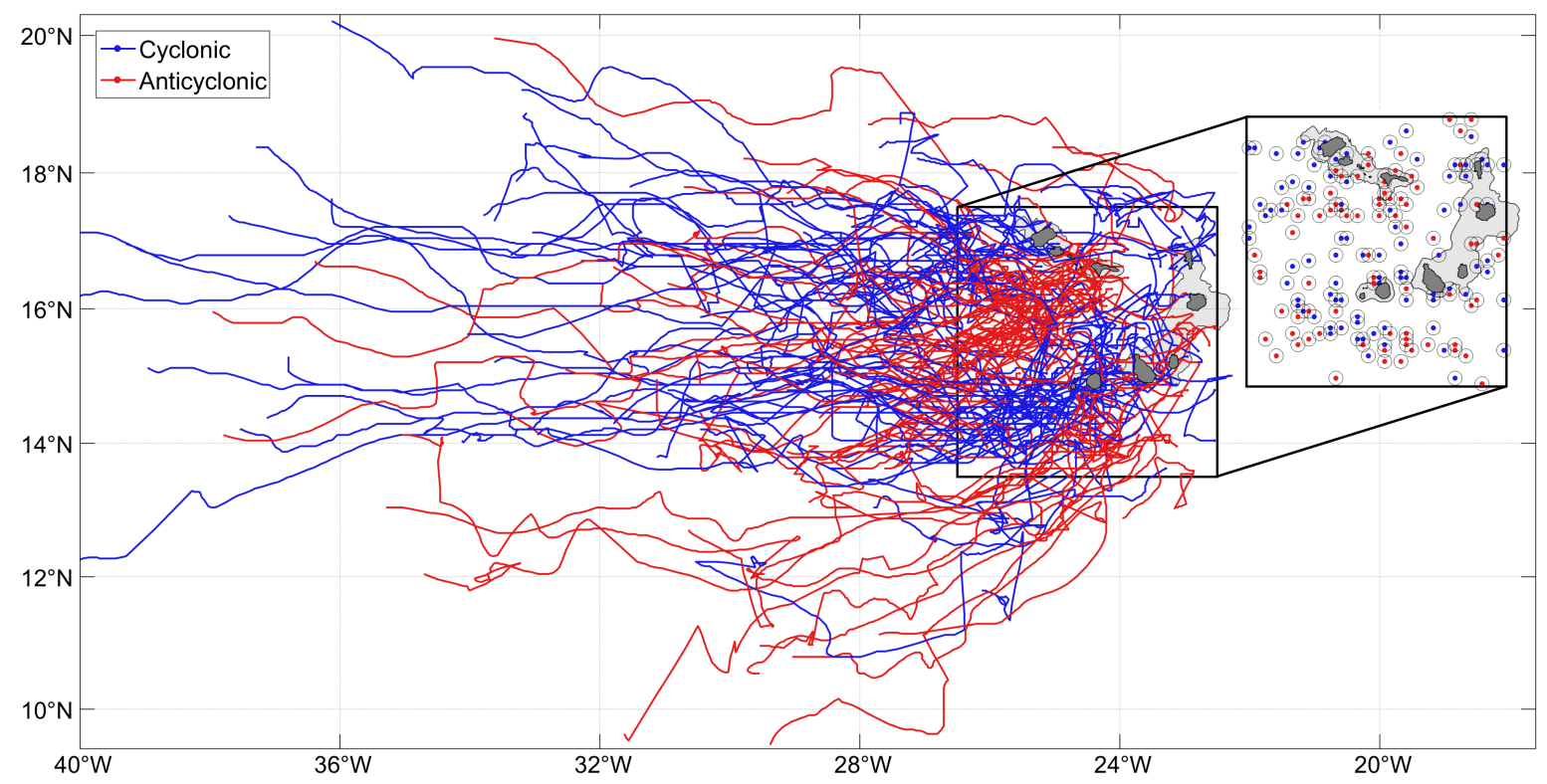

Figure 12: Long-lived ( $\geq 60$ days) island-induced eddy trajectories (main panel) and points of origin (smaller panel). Note the distinct corridors for cyclonic (blue) and anticyclonic (red) eddies.

The most noticeable pattern is, as for the background eddies (Fig. 7), the dominant westward propagation marked by small meridional deflections. As expected, a considerable number of eddies are observed to originate in the lee of ${ }_{915}$ the highest islands (Fogo and Santo Antão). These previously identified eddy hotspots (Fig. 5) are marked by very distinct cyclonic and anticyclonic eddy corridors with a clear southwestward orientation at the western and eastern flank of the islands, respectively. Considering that the 920 western and eastern flanks are characterised by positive and negative wind-vorticity, respectively (Chavanne et al., 2002), it is conceivable that the orographic-disturbed winds have a key role in the generation and propagation of nearfield eddies.

The small number of background anticyclonic tracks intersecting the archipelago through the north (Fig. 7a) increases the likelihood that the anticyclonic eddy corridor south of the windward islands is primarily created by island-induced processes. Conversely, the high number of 930 cyclonic background tracks intersecting these islands indicates that many of the island-induced cyclonic eddies forming the western corridor are directly related to such far-field features, as observed in the island-induced splitting episodes of $\mathrm{C} 1$ and $\mathrm{C} 3$ (Fig. 9a and 9e, respectively).935 Background cyclonic eddies squeezing through the narrow channels can still form "offspring" of opposite sign in the lee of the windward islands - mainly at the eastern flank - as demonstrated in laboratory (Cenedese, 2005) and model (Yang et al., 2017) experiments, though "offspring" ${ }_{940}$ of equal sign occur much more frequently. Near-field eddies are also generated north and east of the archipelago (Fig. 12), but these are most likely driven by the interaction of background eddies with the archipelago (Fig. 7a).
Island induced cyclonic tracks propagate further than anticyclonic, reaching longitudes as far as $\approx 48^{\circ} \mathrm{W}$ and $\approx 38^{\circ} \mathrm{W}$, respectively. The fact that cyclonic eddies are in higher number and live longer than anticyclonic eddies contradicts many past studies (Chaigneau et al., 2009; Sangrà et al., 2009; Chelton et al., 2011). In a theoretical study, Cushman-Roisin et al. (1990) argued that anticyclonic eddies lived longer because they were generally more robust and showed higher tendency to merge, while cyclonic eddies were prone for self-destruction. As a cautionary note, one must consider that merging events may lead us to interpret the premature interruption of eddy tracks as real eddy terminations, when in fact they may still be active but under a different ID.

Current results also demonstrate that most cyclonic and anticyclonic eddies tend to deflect poleward and equatorward, respectively, except in the lee of the islands where most eddies seem to propagate southwestward, in the same direction of the wind (Fig. 4). This general behaviour has been globally (Chelton et al., 2011), regionally (Morrow, 2004; Chaigneau et al., 2009) and locally (Calil et al., 2008; Sangrà et al., 2009) documented, being strongly associated with the combination of the $\beta$-effect and self-advection by nonlinearity (Chassignet \& Cushman-Roisin, 1991; Chelton et al., 2011). Still, background currents in which eddies propagate can have important implications. Sangrà et al. (2009) suggested that the Canary Current was responsible for the initial southward propagation of the anticyclonic eddies forming the Canary Eddy Corridor, which then drifted westward as they became large enough for self-advection due to the $\beta$-effect. It has been also demonstrated that the westward Pacific North Equatorial Current can modify the propagation of eddies generated in the 
of Hawaii (Calil et al., 2008), being even able to increase their propagation speeds in favourable conditions (Holland \& Mitchum, 2001). Considering that eddies generated or 960 modified by the Cape Verde Archipelago propagate in the direction of the Atlantic North Equatorial Current, it is expected that the latter can also affect their propagation.

\subsubsection{Specific cases of island-induced eddies}

The generation and evolution of mesoscale eddies can still be influenced by many other factors, especially in an eddying environment such as Cape Verde. To better comprehend these processes, the period of $31^{\text {st }}$ January 2005970 - $31^{\text {st }}$ August 2005 was selected for the characterisation of 19 eddy trajectories, represented in Fig. 13.
C1 is one of the island-induced eddies with higher lifespan (358 days) and propagation distance (up to $48^{\circ} \mathrm{W}$ ). This eddy was formed in the lee of Fogo when the windstress curl was relatively high $\left(\approx 5 \times 10^{-7} \mathrm{~N} \mathrm{~m}^{-3}\right)$, yet three nearby eddies of opposite sign may have contributed to its formation (not shown). From those that originate near this location (A1.1, C4 and A5.1: Fig. 13a, c and f, respectively), only $\mathrm{C} 4$ seems to be free from the influence of other eddies. A5.1 and A1.1 result from the splitting of the island-induced A5 and background A1, respectively, though atmospheric effects could have contributed to the generation of A1.1. The parent A1 was formed in the east of archipelago and propagated through the leeward island channels, until it intersected an area of strong positive wind-stress curl, changing quite drastically its character-

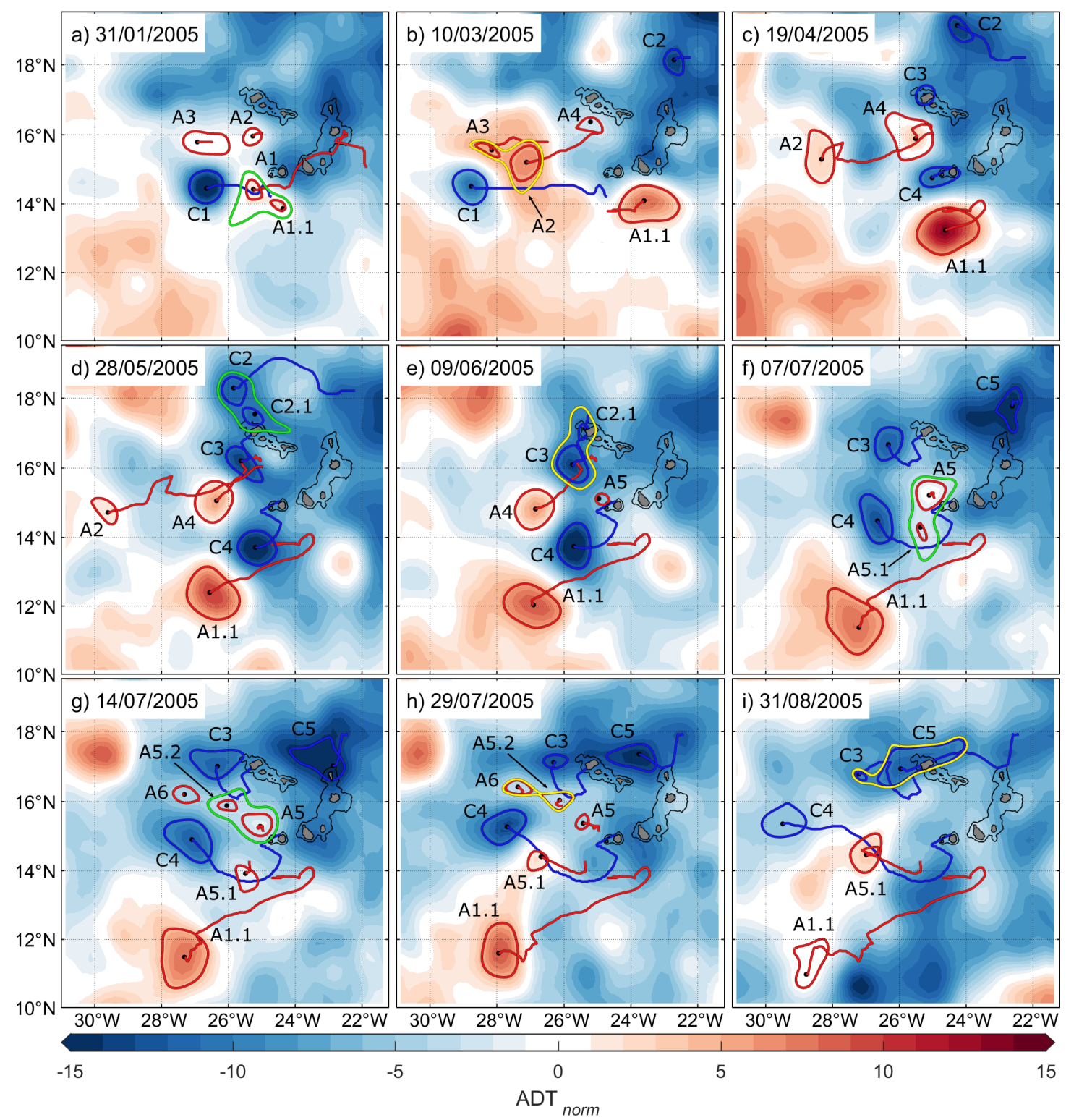

Figure 13: Island-induced eddies evolution snapshots from $31^{\text {st }}$ January 2006 to $31^{\text {st }}$ August 2005, plotted against normalised ADT maps. Blue and red colours represent cyclonic and anticyclonic eddies, respectively. Green and yellow contours represent splitting and merging events, respectively. 
istics before splitting and terminating (discussed later).

The wake of the windward islands is also the birthplace of many other eddies. Despite not related with island ${ }_{\overline{1025}}$ induced processes, the background $\mathrm{C} 2$ is formed northeast of the archipelago (Fig. 13b) and gives origin to the background C2.1 in its westward propagation (Fig. 13d), a splitting event which is apparently not related with topographic effects. It's "offspring" C2.1 on the other hand interacts with Santo Antão and merges the island-induced C3 in the lee side (Fig. 13c), being intersected by the background $\mathrm{C} 5 \approx 3$ months later (Fig. 13i). A5's family tree is a another remarkable example of the complex generation processes behind island-induced eddies, for it is generated in the north of Fogo (Fig. 13e) and is responsible for the generation of 2 other near-field eddies: A5.1 in the south (Fig. 13f) and A5.2 northwest (Fig. 13g). Then the younger "offspring" A5.2 merges the island-induced A6 (Fig. 13h), while the A5.1 propagates westward (Fig ${ }_{1040}$ 13i).

Regarding island-induced eddy propagation characteristics, C3 and C4 deserve special attention. Both eddies are formed in the wake of the tallest islands of the archipelago (Fig. 13c), more precisely in the western flank which was ${ }^{045}$ strongly affected by positive wind-stress curl at that time (not shown). Previous to their formation, A1.1, A2 and A4 originate in the lee of the same islands but at the eastern flank, conversely affected by negative wind-stress curl. These anticyclonic eddies propagate southwestward, fol ${ }_{1050}$ lowing very closely the negative wind-stress curl bands (not shown). C3 and C4 follow an identical pattern at an initial phase as they propagate in close proximity to A1.1 and A4, respectively (Fig. 12d), contradicting the typical northwestward direction observed in Fig. 12 and $_{055}$ in many other studies. As the anticyclonic eddies propagate further away, however, C3 and C4 deflect westward (Fig. 13d and e) and subsequently northward (Fig. 13f, g and $\mathrm{h}$ ).

Kundu \& Cohen (1990) argued that two eddies of opposite sign but similar strength can propagate in parallel lines when in close proximity. Such behaviour was also documented in the Hawaii, where the advection of cyclonic eddies by nearby anticyclonic eddies was attributed as the

1015 main cause (Dickey et al., 2008; Jia et al., 2011). Con $\overline{1065}$ sidering the general south-westward orientation of many cyclonic tracks generated in the wake of the highest islands (Fig. 12) - the main near-field eddy hotspots, Fig. 5c) - current results demonstrate that eddy-eddy interac-

1020 tions are a key factor in the propagation of such features ${ }_{1070}$ although island-induced wind-shear effects must also be taken into account.

\subsection{Wind-mediated eddy generation, intensification and confinement}

Eddies that are effectively impacted by orographic-induced atmospheric effects should follow an identical seasonal behaviour as the wind. The persistent north-easterly trade winds which affect the archipelago are strong and steady during winter and spring, whilst weak during summer and autumn winds (Fig. 3; Varela-Lopes \& Molion, 2014; DGA, 2004). Naturally, such seasonal variation is reflected in the wind-stress curl, as dipoles of positive (divergent) and negative (convergent) wind-stress curl are more intense and reach highest extension during winter and spring (Fig. $14 \mathrm{a} / \mathrm{e}$ and $\mathrm{b} / \mathrm{f}$, respectively). Tough not reflected in the seasonal long-lived eddy origins (Fig. 6 upper panels), similar seasonal patterns are also depicted in the EKE fields (Fig. 6 lower panels) - especially in the leeward islands where the wind regime is more constant (DGA, 2004). Besides Chavanne et al. (2002), such far-reaching atmospheric effects were documented by Chelton (2004) when discussing the existence of persistent small-scale features at a global scale, arguing that these previously unresolved features could have substantial impacts on the global ocean.

Fig. 14 shows that long-lived cyclonic and anticyclonic eddies form mostly in the positive and negative wind-stress curl areas, respectively, but this is only evident when the wind-stress curl is more pronounced (Fig. 14a/e and b/f). Such pattern is perfectly illustrated in the deep channel between Fogo and Santiago, characterised by positive windshear vorticity and by the general dominance of cyclonic eddy origins in winter and spring (Fig. 14a). The same applies for the anticyclonic eddies formed in the negative wind-stress curl wake of the leeward islands in winter (Fig. $14 \mathrm{e})$.

Besides the birth places, cyclonic eddies tend to propagate almost exclusively through the positive (red) windstress curl areas depicted in the western flanks of Santo Antão's and Fogo's wake during winter and spring (Fig. $14 \mathrm{a}$ and b, respectively), whereas anticyclonic tracks follow very closely the negative (green) wind-stress curl areas in the opposite flanks (Fig. 14e and f). In contrast, eddy trajectories appear to be much more disorganized and are more westward-oriented during summer and autumn (Fig. $14 \mathrm{c} / \mathrm{g}$ and $\mathrm{d} / \mathrm{h}$, respectively). One should note that eddy trajectories are split according to the season in which they are active. This means that all anticyclonic eddies propagating in the wake of the leeward islands during spring and summer (Fig. 14f and g, respectively) were first detected in winter (Fig. 14e).

Albeit not represented in Fig. 14, such far-reaching atmospheric effects may also explain the south-westward orientation of the anticyclonic background eddy trajectories previously observed in the wake of the leeward islands (Fig. 7a). This cluster of background and island-induced 


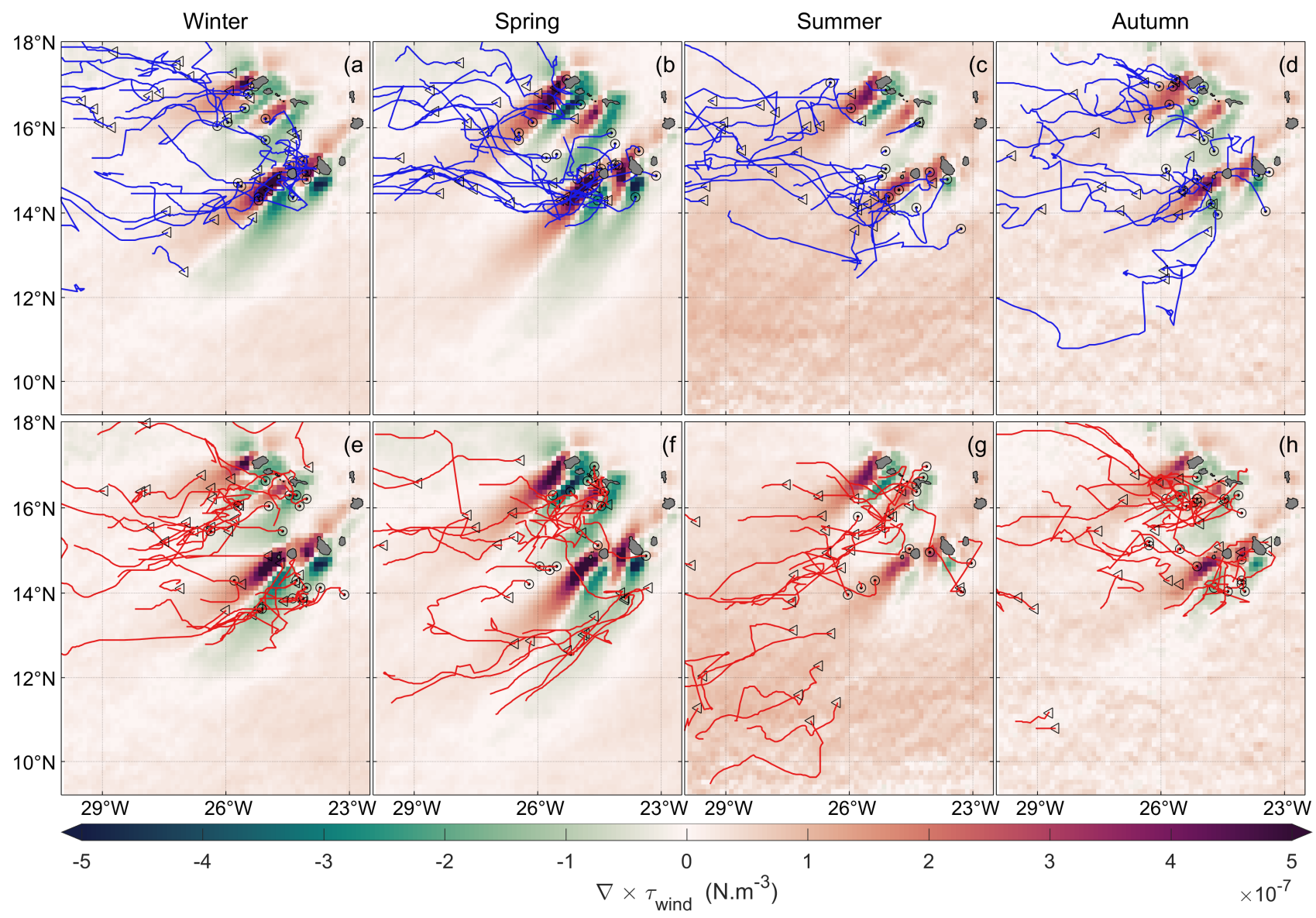

Figure 14: Seasonal mean wind-stress curl in Cape Verde Archipelago, overlapped by long-lived ( $>60$ days) island-induced cyclonic (blue) and anticyclonic (red) eddy tracks. Only eddies (139) generated within the wind-stress curl bands are represented. Circled points and left-pointing triangles represent the place of origin and the resumption of the trajectory interrupted in the previous season.

anticyclonic eddy tracks resembles with great detail the Canary Eddy Corridor described by Sangrà et al. (2009). These authors presented strong evidences that the windshadow effect induced by the Canary Islands plays a key role in the generation of long-lived eddies, which initially propagate south and then tend to deflect south-westward. The authors also suggested that similar long-lived eddy corridors could be present in other oceanic regions, referring to the Hawaiian Archipelago as an example (Calil et al., 2008). Schütte et al. (2016a) also reported similar findings, as a significant number of anticyclonic ed ${ }^{111}$ dies formed a distinct south-westward pathway in the lee of Fogo. Furthermore, Couvelard et al. (2012) presented strong theoretical evidences that eddies generated by wind shear in the lee of Madeira Island were "trapped" in the wind-wake region, as the cyclonic and anticyclonic eddies ${ }^{111}$ propagated through the positive and negative wind-stress curl bands, respectively. Apart from having strong reasons to believe that this anticyclonic eddy pathway represents another important long-lived eddy corridor in the Atlantic Ocean, current results also demonstrate that the ${ }^{120}$ orographic-disturbed winds may be an important contributor to the containment of both incoming background and island-induced eddies.

\subsubsection{Ekman pumping velocities}

Eddy-wind interaction can also give rise to ageostrophic circulations and consequent vertical transports of water within eddies, a process generally known as Ekman pumping $\left(\omega_{E k} ;\right.$ Stern, 1965; Niiler, 1969). It is thus reasonable to use the absolute $\omega_{E k}$ velocities as a proxy to determine the impact of the island-disturbed winds on transiting background and island-induced eddies. The linear term (e.q. 7) is directly related to the effect of the windstress on eddy-driven surface currents. Assuming a uniform wind-stress applied to a radially symmetric eddy, wind-stress is higher/lower on the flanks of the eddy where the current is in the opposite/same direction of the wind (McGillicuddy, 2016). This divergence in wind-stress induces upwelling/downwelling in the interior of a Northern hemisphere anticyclonic/cyclonic eddy (Martin \& Richards, 2001; Gaube et al., 2013). The nonlinear-term (e.q. 8) on the other hand is associated with the advection of the interior relative vorticity $(\zeta)$ by the wind-stress. Consequent fine-scale lateral gradients in $\zeta$ result in the convergence/divergence of the Ekman transport which in turn induces vertical motions within the eddy, often forming a dipole consisting of a downwelling and a upwelling cell in 


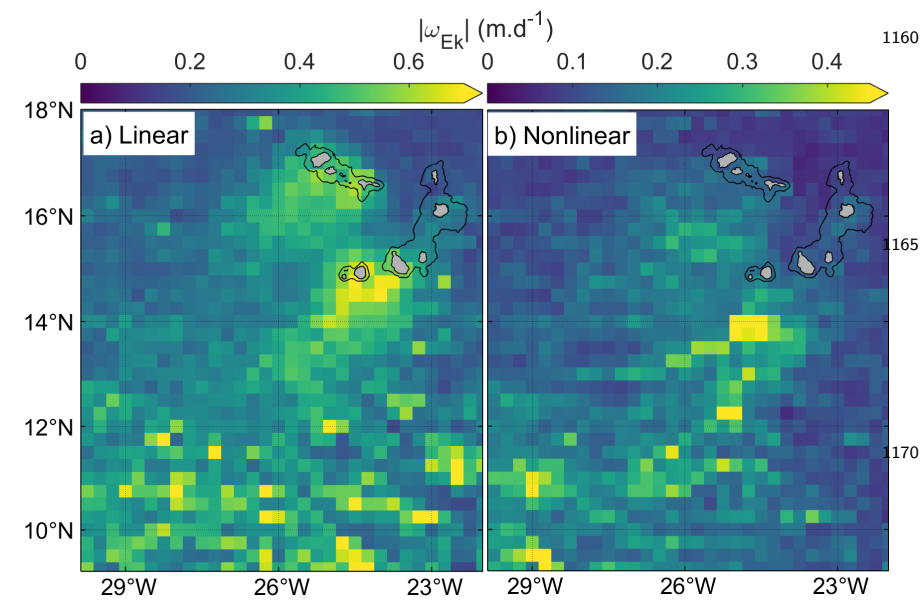

Figure 15: Average (a) linear and (b) nonlinear absolute Ekman pumping velocities within long-lived eddies which centroid passes by each $1 / 4^{\circ}$ bin. Note the different scales, used to emphasize spatial patterns.

each side (McGillicuddy et al., 2008; Mahadevan et al., Given the highly irregular and strong wind vorticity in the lee of the islands, however, we should not expect such idealized mechanisms to occur but instead much more complex patterns. Furthermore, nonlinear $\omega_{E k}$ velocities are likely to be underestimated due to the coarse resolution of altimetry-derived geostrophic currents, insufficient to capture submesoscale processes (Mahadevan et al., 2008).

Nevertheless, vertical velocities resultant from gradients in wind-stress are more pronounced in the lee of the windward and leeward islands, where highest linear $\left|\omega_{E k}\right|$ reacht $^{175}$ eral bins with high linear $\left|\omega_{E k}\right|$ velocities are scattered between $9-12^{\circ} \mathrm{N}$, but these are most likely provoked by the small number of long-lived eddies passing by (Fig. 17d) and should be neglected. Nonlinear $\left|\omega_{E k}\right|$ velocities are ${ }^{180}$ 140 lower in magnitude but follow a similar pattern as the linear component (Fig. 15b). Nonetheless, nonlinear velocities are more significant in the lee of the leeward islands $\left(0.45 \mathrm{~m} \mathrm{~d}^{-1}\right)$ where they form a south to south-westward corridor identical to the anticyclonic eddy corridor de $\mathbf{1}^{1185}$ 145 picted in Fig. 7 and 14. In fact, the nonlinear component of $\omega_{E k}$ is expected to be larger for anticyclonic eddies because negative vorticity opposing the planetary rotation decreases the eddy's net rotation $(\zeta+f)$ and stimulates a greater response in vertical velocities, whilst the opposite $\mathrm{G}_{190}$ occurs when the net rotation increases by the same amount (Mahadevan et al., 2008). Although this mechanism is less significant in the lee of the windward islands - probably due to the fact that anticyclonic eddies are less-energetic (Fig. 17f) - we have strong reasons to believe that such $_{195}$ 155 distinct nonlinear $\left|\omega_{E k}\right|$ velocities are directly related the formation of the anticyclonic eddy corridor.

Average $\left|\omega_{E k}\right|$ velocities within long-lived eddies intersecting the areas of strong wind-stress curl (Fig. 14) are quantified in Table 1 , where a distinction is made be ${ }^{1200}$ tween when these eddies are outside and inside the island wakes. The linear component is dominant inside and outside the wakes, demonstrating that gradients in the horizontal Ekman transport are the primary contributor for the vertical transport of water in the interior of eddies. Nevertheless, the nonlinear component has a greater role when eddies are outside, accounting for $34 \%$ instead of $30 \%$ of the total $\left|\omega_{E k}\right|$. Highest linear and nonlinear average $\left|\omega_{E k}\right|$ occur when eddies are under the influence of orographic-perturbed winds, being their combination $0.20 \mathrm{~m} \mathrm{~d}^{-1}$ greater than when outside the influence of the islands. Furthermore, anticyclonic eddies are the ones with greater linear and nonlinear vertical velocities inside and outside the wake.

Table 1: Average linear, nonlinear and total absolute Ekman pumping velocities within all long-lived eddies before/after intersecting ("Open Ocean") and when inside ("Wake") the island wakes. Highest values between both groups are highlighted in bold.

\begin{tabular}{|c|c|c|c|c|}
\hline$\left|\omega_{E k}\right|$ & & & Open & cean \\
\hline$\left(m \cdot d^{-1}\right)$ & Cyclonic & Anticyc. & Cyclonic & Anticyc. \\
\hline Linear & 0.38 & 0.51 & 0.23 & 0.36 \\
\hline & 0.44 & $70 \%)$ & 0.29 & $66 \%)$ \\
\hline Nonlinear & 0.14 & 0.25 & 0.11 & 0.21 \\
\hline & 0.19 & $30 \%)$ & 0.15 & $34 \%)$ \\
\hline Total & 0.52 & 0.75 & 0.33 & 0.57 \\
\hline & & & & \\
\hline
\end{tabular}

In order to determine how rotational velocities $\left(V_{\max }\right)$, radius $\left(R_{\max }\right)$ and linear and nonlinear $\left|\omega_{E k}\right|$ velocities respond as eddies interact with orographic-perturbed winds, the dynamic evolution of three eddies previously represented in Fig. 13 is presented in Fig. 16. The influence of favourable positive wind-stress curl acting upon the perimeter of $\mathrm{C} 1$ is quite evident (Fig. 16a), as $V_{\max }$ intensifies according to the wind-stress curl and reaches $0.58 \mathrm{~m} \mathrm{~s}^{-1}$ maximum velocity. When the wind-stress curl is no longer significant, $V_{\max }$ decreases until it stabilizes at $\approx 0.37 \mathrm{~m} \mathrm{~s}^{-1}$. Linear $\left|\omega_{E k}\right|$ velocities are generally dominant over nonlinear but do not exceed $0.52 \mathrm{~m} \mathrm{~d}^{-1}$.

A1 one the other hand presents much more pronounced vertical transports (Fig. 16b). Linear $\left|\omega_{E k}\right|$ velocities rise as A1 propagates through the islands channel into the lee of Fogo in mid December, being subsequently followed by $V_{\max }$ and then by nonlinear $\left|\omega_{E k}\right|$ velocities - most likely as a feedback mechanism driven by the increase in $V_{\max }$. Similarly to $\mathrm{C} 1, V_{\max }$ in A1 stabilizes and decreases when under the influence of unfavourable (positive) windstress curl. Linear and nonlinear $\left|\omega_{E k}\right|$ reach maximum velocities of $\approx 1.42$ and $0.63 \mathrm{~m} \mathrm{~d}^{-1}$, respectively, when $V_{\max }>0.2 \mathrm{~m} \mathrm{~s}^{-1}$ but then decrease concurrently to $V_{\max }$. Oscillations in A1's $R_{\max }$ are probably due to bathymetric effects, with the exception of the sudden decrease in the final days of January when A1 intersects strong positive wind-stress curl. Such unfavourable conditions could 


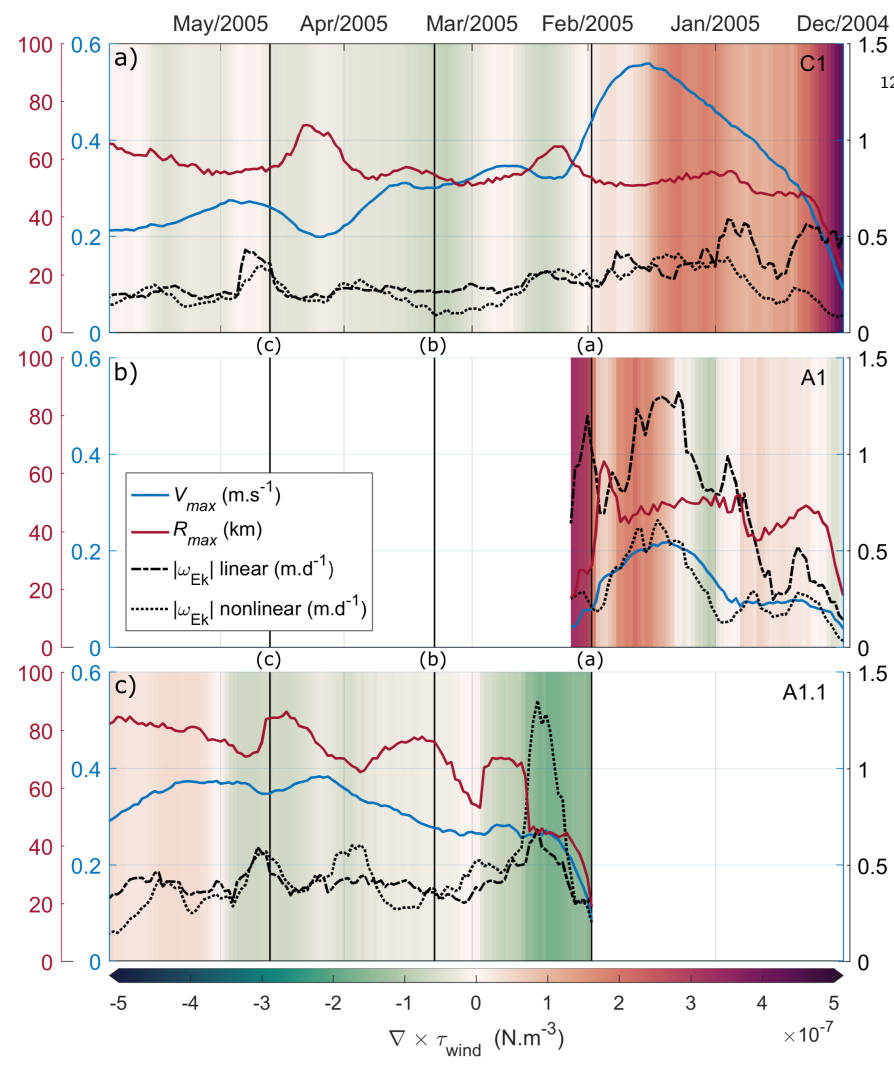

Figure 16: Evolution of (a) C1, (b) A1 and (c) A1.1 represented in Fig. 13. Background colours represent the mean 8-day averaged wind-stress curl within the eddy's perimeter. Black vertical lines mark the snapshots from Fig. 13. Horizontal axis is oriented from right to left.

have contributed to a drastic decrease in $R_{\max }$ (from 60 to $20 \mathrm{~km}$ ) and $V_{\max }$ (from 0.15 to $0.04 \mathrm{~m} \mathrm{~s}^{-1}$ ), splitting and giving rise to A1.1 before dissipating a few days later.

The "child" A1.1 (Fig. 16c) is generated under favourable (negative) wind-stress curl and presents significant dominant nonlinear $\left|\omega_{E k}\right|$ velocities that reach $1.4 \mathrm{md}^{-1}$ in the lee of Fogo (Fig. 13a). Likewise C1 and A1, the evolution of A1.1's $V_{\max }$ follows the favourable wind-stress curl acting upon its perimeter, showing an opposite behaviour $\mathrm{r}_{230}$ as C1's $V_{\max }$ which is on the other hand influenced by unfavourable curl from February onwards.

\subsection{Eddy statistics and kinematic properties}

The long-lived background and island-induced mean eddy properties are presented in Table 2, together with maps il1215 lustrating mean properties of the long-lived eddy field in Fig. 17. From the 142 eddies that reach Cape Verde, 82 are cyclonic and 60 are anticyclonic, whereas 91 cycloniq $_{240}$ and 82 anticyclonic of a total of 173 eddies are generated inside CV (Table 2). Nonetheless, the number of longlived island-induced eddies is likely underestimated due to the probability of splitting or merging when interacting with other eddies. Cyclonic are dominant over anticyclonic eddies for both background and island-induced ${ }^{245}$ groups, with a minor difference of 1-2 eddy $\mathrm{yr}^{-1}$. As the lifetime threshold increases the cyclonic supremacy accentuates, especially for island-induced eddies (not shown).

Table 2: Mean properties of the island-induced and background cyclonic and anticyclonic long-lived eddies. Highest values between both grups are in bold.

\begin{tabular}{|c|c|c|c|c|}
\hline \multirow[b]{3}{*}{ Detected eddies } & \multicolumn{2}{|c|}{ Island-induced } & \multicolumn{2}{|c|}{ Background } \\
\hline & Cyclonic & Anticyc. & Cyclonic & Anticyc. \\
\hline & $\begin{array}{c}91 \\
\left(8 \mathrm{yr}^{-1}\right)\end{array}$ & $\begin{array}{c}\mathbf{8 2} \\
\left(7 \mathrm{yr}^{-1}\right)\end{array}$ & $\begin{array}{c}82 \\
\left(7 \mathrm{yr}^{-1}\right)\end{array}$ & $\begin{array}{c}60 \\
\left(5 \mathrm{yr}^{-1}\right)\end{array}$ \\
\hline Lifetime (days) & & & 16 & 71 \\
\hline $\max$ & $\begin{array}{c}157.23 \\
403\end{array}$ & $\begin{array}{c}143.91 \\
430\end{array}$ & $\begin{array}{c}169.93 \\
638\end{array}$ & $\begin{array}{c}157.48 \\
370\end{array}$ \\
\hline Travel distance & & & 89 & 45 \\
\hline $\begin{array}{l}(\mathrm{km}) \\
\max \end{array}$ & $\begin{array}{c}842.81 \\
2698.89\end{array}$ & $\begin{array}{c}761.73 \\
2477.91\end{array}$ & $\begin{array}{c}915.43 \\
3245.15\end{array}$ & $\begin{array}{c}869.46 \\
2300.33\end{array}$ \\
\hline $\begin{array}{l}\text { Propa. speed } \\
\left(\mathrm{km} \mathrm{d}^{-1}\right)\end{array}$ & $5.33^{5}$ & 5.29 & $5.54^{5}$ & O 5.46 \\
\hline Radius (km) & & & & \\
\hline $\max$ & $\begin{array}{c}52.72 \\
192.93\end{array}$ & $\begin{array}{c}50.45 \\
193.35\end{array}$ & $\begin{array}{c}53.55 \\
172.03\end{array}$ & $\begin{array}{c}51.14 \\
136.52\end{array}$ \\
\hline $\begin{array}{l}\text { Rotational speed } \\
\left(\mathrm{m} \mathrm{s}^{-1}\right) \\
\max \end{array}$ & $\begin{array}{l}0.14^{\mathbf{0}} \\
0.57\end{array}$ & $\begin{array}{l}0.13 \\
0.45\end{array}$ & $\begin{array}{l}0.11 \\
0.37\end{array}$ & $\begin{array}{l}0.12 \\
0.39\end{array}$ \\
\hline $\begin{array}{l}\operatorname{EKE}\left(\mathrm{cm}^{2} \mathrm{~s}^{-2}\right) \\
\max \end{array}$ & $\begin{array}{r}\mathbf{1 1} \\
126.72 \\
1625.02\end{array}$ & $\begin{array}{l}09 \\
109.46 \\
1005.56\end{array}$ & $\begin{array}{l}81.66 \\
695.18\end{array}$ & $\begin{array}{c}88.52 \\
751.97\end{array}$ \\
\hline $\begin{array}{l}\text { Vortex rossby } \\
\text { number } \\
\max \end{array}$ & $\begin{array}{l}0.15^{\mathbf{0}} \\
0.62\end{array}$ & $\begin{array}{l}\mathbf{5} \\
0.15 \\
0.45\end{array}$ & $\begin{array}{l}0.11 \\
0.38\end{array}$ & $\begin{array}{l}2 \\
0.13 \\
0.52\end{array}$ \\
\hline Nonlinearity $(U / c)$ & $\begin{array}{l}3.97^{3} \\
86.17\end{array}$ & $\begin{array}{l} \\
\quad 3.70 \\
129.73\end{array}$ & $\begin{array}{c}3 \\
3.47^{3} \\
117.10\end{array}$ & $\begin{array}{l}9 \\
3.50 \\
0.52\end{array}$ \\
\hline
\end{tabular}

Background eddies have on average slightly higher lifetime expectancy than island-induced eddies $(\approx 164$ and 151 days, respectively; Table 2), likely because the former need to propagate longer distances and thus be active for longer periods to be considered as such. Naturally, background eddies propagate on average longer distances which is somewhat expected, considering the high correlation between these two variables $\left(\mathrm{R}^{2}=0.91\right)$. Current eddy lifespan exceeds quite significantly the ones from Schütte et al. (2016a), who reported an average of 28 days and a maximum of 280/180 days for anticyclonic/cyclonic eddies in the region. This can be explained by the different thresholds applied ( $>7$ days and $>45 \mathrm{~km}$ radius) and to the the smaller study area and consequent restriction on eddy trajectories.

Eddy splitting is observed more frequently in the interior of the archipelago, mainly in the lee of Santo Antão as it was the case of previously observed C1 and C3 (Fig. $9 \mathrm{~b}$ and $\mathrm{e}$ ) - and in the north and south of Fogo (Fig. 17a) - 
as it was the case of A1 and A5 (Fig. 13a and f) - meaning that island-induced eddies can likewise contribute to the formation of local "offspring". On the other hand, merging events are more concentrated in the north-easternmost islands (Fig. 17b), likely associated with the interaction 305 of incoming background eddies with the islands.

It is in the eastern and northern side of the archipelago where eddies remain for longer periods ( $\geq 16$ days, Fig. $17 \mathrm{c})$, most likely due to the topographic obstruction of incoming background eddies by the islands. High residence periods are also depicted in the south of the leewards islands, coinciding with the background and island-induced anticyclonic eddy corridor (Fig. 7a and 12, respectively). In fact, the lower-than-expected number of eddy origins in this region in Spring (Fig. 6b) is very likely related with such high residence periods. Background eddies generated near the Mauritanian coast and Cape Vert headland spend on average $\approx 2$ weeks at each $1 / 2^{\circ}$ bin before propagating offshore.

Regarding the near-field, long-lived eddies were more frequently detected in the lee of the windward islands $(\geq$ 25, Fig. 17), though the leeward islands also recorded at least 20 different eddies. High values are still depicted in the north of the windward islands - likely related to the high number of background cyclonic eddy tracks observed in Fig. $7 \mathrm{a}$ - and in the leeward islands - representative of the background and island-induced anticyclonic eddy corridor.

Island-induced eddies propagate on average at a lower ${ }_{330}$ speed than background eddies $\left(5.31\right.$ and $5.50 \mathrm{~km} \mathrm{~d}^{-1}$, respectively; Table 2), likely due to topographic-induced drag and eddy-eddy interactions within CV area. Besides being active for longer periods and propagating for longer distances, cyclones propagate (on average) at higher speeds than anticyclones. The westward propagation speed for long-lived eddies is remarkably close to the phase speeds of nondispersive baroclinic Rossby waves (Chaigneau et al., 2009; Chelton et al., 2011), which in turn increase towards the equator as a function of the planetary vorticity gradient effect ( $\beta$, Cushman-Roisin et al., 1990; Van Camp ${ }^{134}$ et al., 1991). In fact, Polito \& Sato (2015) demonstrated that eddies often propagate on crests and troughs of planetary Rossby waves, mostly in lower latitudes. Current eddy propagation speeds are $\approx 2 \mathrm{~km} \mathrm{~d}^{-1}$ higher than the ones reported by Schütte et al. (2016a), but still within ${ }^{134}$ the range of the zonally averaged westward phase speed of Rossby waves (varies from $\approx 5.5-17.2 \mathrm{~km} \mathrm{~d}^{-1}$ between $22^{\circ}-9^{\circ} \mathrm{N}$, respectively) and close to the values reported by Chelton et al. (2011) for this region.

The influence of the local planetary rotation rate $(f)$ on the propagation of an eddy is also directly proportional to the eddy's diameter (Cushman-Roisin et al., 1990; Sangrà et al., 2009). Hence, the higher the eddy's size, the higher the $\beta$-effect. Island-induced eddies have in general slightly335 lower $R_{\max }$ than background eddies $(51.59$ and $52.35 \mathrm{~km}$, respectively; Table 2). Such pattern is reflected in the Fig. $17 \mathrm{e}$ and is likely related to the topographic constrain and consequent squeezing of eddies passing by the narrow island channels. Nonetheless, the maximum value for $R_{\max }$ is observed in an island-induced anticyclonic eddy (193.93 $\mathrm{km}$, Table 2). Average $R_{\max }$ increases from $\approx 40$ to $80 \mathrm{~km}$ between $22^{\circ}-9^{\circ} \mathrm{N}$, respectively (Fig. $17 \mathrm{~d}$ ), being directly related to the local Rossby radius of deformation $\left(R_{d}\right)$ that increases torwards the equator and is found to be very close to $R_{\max }$ at these latitudes (Chelton et al., 1998). One should note that the eddy's scale is highly dependent on the coarse altimetry spatial resolution $\left(1 / 4^{\circ}\right.$, or $\left.\approx 28 \mathrm{~km}\right)$. Le $\mathrm{Vu}$ et al. (2018) warned that the AMEDA algorithm could only accurately detect eddies with $R_{\max } \geq R_{d}$ and may not provide valid information for eddies with $R_{\max }<$ $50 \mathrm{~km}$ when using a $1 / 4^{\circ}$ gridded dataset. Considering that the local $R_{d} \approx 40-80 \mathrm{~km}$, current results should be regarded with caution. Nonetheless, we assume that spurious eddy signals are effectively removed when applying a 60-day lifetime threshold.

Average and maximum $V_{\max }$ are 0.02 and $0.18 \mathrm{~m} \mathrm{~s}^{-1}$ greater for island-induced eddies than for background eddies (Table 2). Naturally, EKE values follow the same pattern, being on average $48 \mathrm{~cm}^{2} \mathrm{~s}^{-2}$ greater for islandinduced eddies. Such behaviour is reflected in Fig. 17f, where distinct areas of high $V_{\max }$ are easily depicted in the lee of the windward and leeward islands, being more pronounced in the south and southwest of the leeward islands where $V_{\max }$ reaches on average $\approx 0.27 \mathrm{~m} \mathrm{~s}^{-1}$. Nevertheless, it is important to note that geostrophic surface velocities computed from altimetry products tend to be underestimated due to the coarse resolution and consequent smoothing of vortices with a $R_{\max }$ close to the ADT resolution (Caldeira et al., 2014; Mkhinini et al., 2014).

The vortex Rossby number ( $R o$ ) quantifies the relative vorticity normalized by earth's rotation rate. Hence, an eddy is highly nonlinear and centrifugal instability is likely to occur when $R_{o}>1$, whereas $R o<1$ indicates a strong influence of the planetary rotation and eddy currents dominated by the cyclogeostrophic balance between the pressure gradient force and the Coriolis acceleration (Stegner, 2014; Chelton et al., 2011; Mkhinini et al., 2014). Background and island-induced eddies are characterized by moderate average $R o$ of 0.12 and 0.15 , respectively, although maximum can reach values in the order of 0.52 and 0.62 (Table 2). Highest mean Ro are found in the lee of the leeward islands (Fig. 12g) where distinct bands of positive/negative Ro at the western/eastern flanks indicate the dominance of cyclonic/anticyclonic eddies. The fact that this $R o$ dipole coincides quite remarkably with the ones depicted in the seasonal-averaged wind-stress curl (Fig. 14) further supports the hypothesis that the islandinduced wind-shear is a key factor for eddy generation, propagation and intensification. Two other conspicuous cyclonic and anticyclonic eddy "pathways" are perceivable in the northern/western and in the southern/eastern 

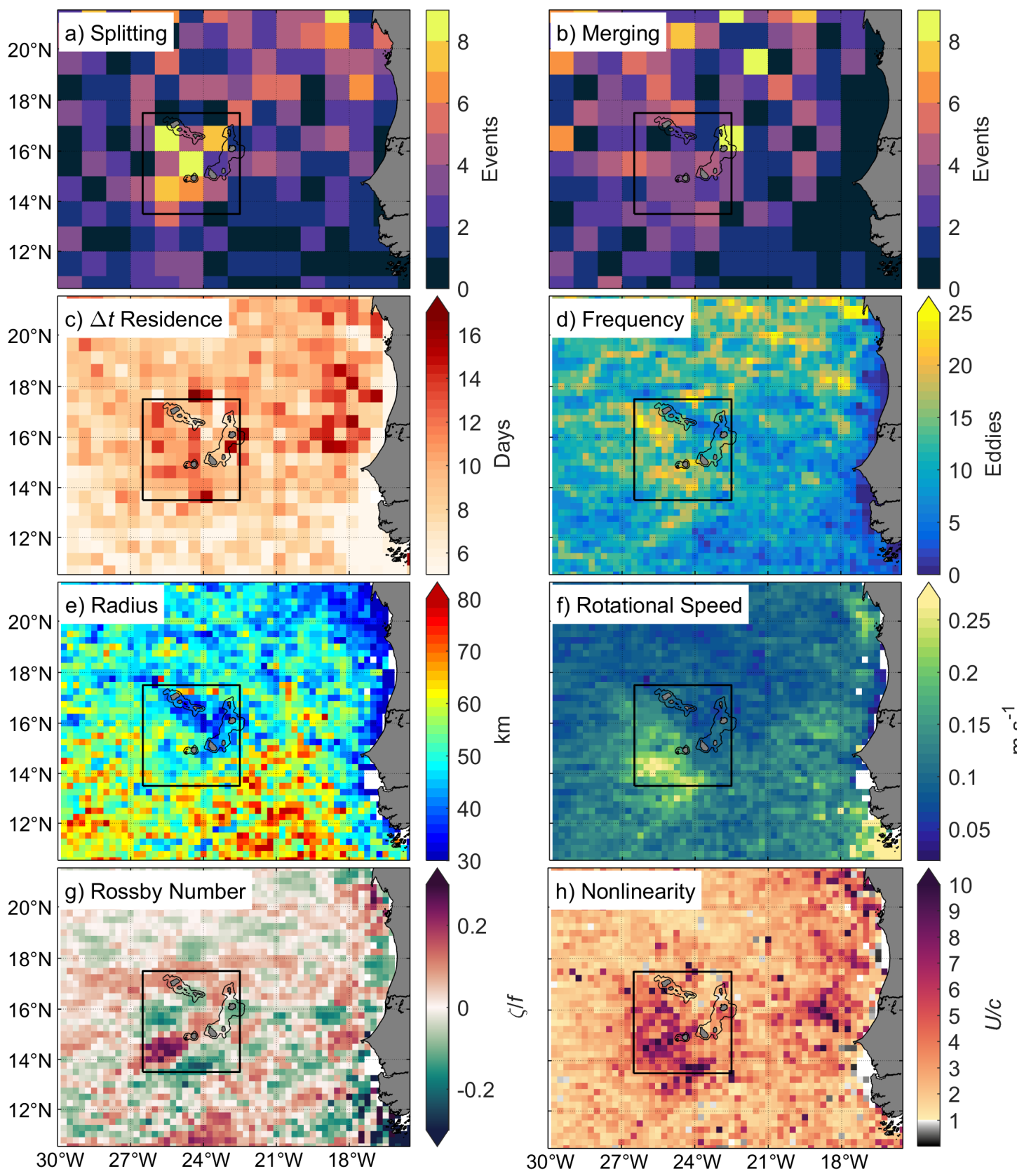

Figure 17: Geographic distribution for: number of (a) merging and (b) splitting events for every $1^{\circ}$ pixel; (c) mean eddy residence time for every $1 / 2^{\circ}$ pixel; and mean eddy (d) frequency ; (e) radius $\left(R_{\max }\right)$, f) rotational speed $\left(V_{\max }\right)$; $(\mathrm{g})$ vortex Rossby number and $(\mathrm{h})$ nonlinearity for every $1 / 4^{\circ}$ pixel. From $(\mathrm{c})$ to $(\mathrm{h})$ each pixel represents the average values of the eddy whose centroid passes within the bin. Black thick lines represent the CV area.

side of the windward islands, respectively, being in perfect agreement with the long-lived background (Fig. 7a) and island-induced eddy trajectories (Fig. 12).

Another valuable metric for nonlinearity goes by the $\mathrm{ra}^{137}$ tio between $V_{\max }$ and eddy translation speed $(c)$. For $V_{\max } / c>1$, fluid is effectively advected within the eddy (Chelton et al., 2011) and the exchange of water with the surrounding environment is reduced (Schütte et al., 2016a). As expected, both background and island-induced ${ }^{37}$ are nonlinear by definition, with average values that reach
3.49 and 3.84 , respectively (Table 2). In conformity with current results, Chelton et al. (2011) determined that almost $90 \%$ of the long-lived eddies (lifetime $\geq 112$ days) within the tropical band $\left(20^{\circ} \mathrm{S}-20^{\circ} \mathrm{N}\right)$ were nonlinear, and all eddies outside this band were highly nonlinear. Furthermore, Schütte et al. (2016a) determined that all eddies detected in the Cape Verde region were nonlinear, with $60 \%$ and $4 \%$ having $V_{\max } / c>5$ and 10 , respectively. Naturally, spatial patterns of nonlinearity (Fig. 17h) mirror the ones observed for $V_{\max }$ and Ro (Fig. $17 \mathrm{f}$ and g, respectively). They also indicate that background eddies 
generated in the African coast (mainly near Cape-Vert) ${ }_{430}$ are prone to transport water with distinct characteristics to the Cape Verde Archipelago.

\subsection{Biological impacts}

The enhancement of primary production is largely associated with the supply of nutrients into the euphotic zone (Arístegui et al., 1997; Basterretxea et al., 2002). Accordof Cape Verde is mostly regulated by 3 mechanisms:

(i) The seasonal coastal upwelling in the western African coast stimulates phytoplankton growth (Demarcq \& Somoue, 2015), which sometimes reaches the Cape Verde Archipelago through ocean current or filament advection (Fernandes et al., 2005; Lathuilière et al. ${ }^{1445}$ 2008). In fact, it has been estimated that half of the total upwelled water between $17-23^{\circ} \mathrm{N}$ flows across the upwelling front through filaments (Kostianoy \& Zatsepin, 1996).

(ii) Atmospheric deposition of iron-rich Saharan dust can intensify phytoplankton growth, though with less pronounced implications (Pradhan et al., 2006; Fischer et al., 2016; Ohde \& Siegel, 2010). velocities and high $\mathrm{Chl} a$ concentrations re-emerge in the interior of A1.1 (Fig. 18e), increasing progressively in the north of Sal (Fig. 18f) until the phytoplankton bloom vanishes once again after a northward deflection in the eddy's trajectory (Fig. 18g). A1 and A1.1 were studied by Karstensen et al. (2015) and Fischer et al. (2016), who assumed the splitting of A1 as an interruption in the eddy track and considered both eddies as one single anticyclonic mode-water (or intrathermocline) eddy. These authors also detected a phytoplankton bloom within the eddy perimeter but referred to it as a continuous single bloom, when in fact there are two separate blooms, prior and following the splitting event.

Intrathermocline eddies are defined by an homogeneous volume of water that creates a subsurface lens-like structure, depicted by the dooming/dipping of the isopycnals torwards the eddy core above/below a subsurface swirl velocity maximum (Caldeira et al., 2014; Karstensen et al., 2015). This kind of eddies often promote the vertical transport of cold, nutrient-rich water into the euphotic layer through linear and nonlinear Ekman pumping mechanisms still not fully understood and under strong debate (Gaube et al., 2014; Schütte et al., 2016b; McGillicuddy et al., 2008; Mahadevan et al., 2008; McGillicuddy et al., 2007). Naturally, such processes favour the occurrence of phytoplankton blooms in surface waters (Karstensen et al., 2017; Gaube et al., 2014) and only through enhanced levels of Chl $a$ and negative SST anomalies can the distinction between normal and mode-water anticyclonic eddies be made with remote sensing techniques (Schütte et al., 2016b). Karstensen et al. (2015) documented severe hypoxic conditions (Dissolved Oxygen $(\mathrm{DO})<2 \mu \mathrm{mol} \mathrm{kg}{ }^{-1}$ ) at $42-\mathrm{m}$ depth when A1.1 intersected the Cape Verde Ocean Observatory mooring, north of São Vicente. These conditions were found within the 50-m thick subsurface mode water lens, centered at $\approx 70-\mathrm{m}$ depth. Below this cap, A1.1's vertical structure resembled a normal anticyclonic eddy with downward-bent isopycnals that extended up to 1400 $m$ depth, a fact that can easily explain the topographicinduced northward deflection in the eddy's trajectory. Such DO depleted eddies are now thought to be recurrent in the region and are directly related with the high primary productivity at the surface and subsequent oxygen consumption induced by the sinking of organic matter, which in combination with the isolation of the upper layers against exchanges with surrounding waters creates "dead-zones" in the open ocean (Karstensen et al., 2015, 2017; Fischer et al., 2016; Hauss et al., 2016; Schütte et al., 2016b).

Two other background anticyclonic mode-water eddies are depicted amid this period. A3 arises far from the Mauritanian coast with high levels of Chla (Fig. 18b and c), but the bloom is left behind as the eddy propagates westward and terminates without intersecting the archipelago (Fig. 18d, e and f). On the other hand, A2 is generated near the Cape-Vert headland in the $28^{\text {th }}$ of July and is observed to propagate towards the archipelago with no significant levels of Chla (Fig. 18a and b). At the time it intersects the easternmost islands moderate $\mathrm{Chl} a$ concentrations $\left(\approx 0.50 \mathrm{mg} \mathrm{m}^{-3}\right)$ emerge within the eddy, leaving the phytoplankton patch in the vicinity of the islands af- 

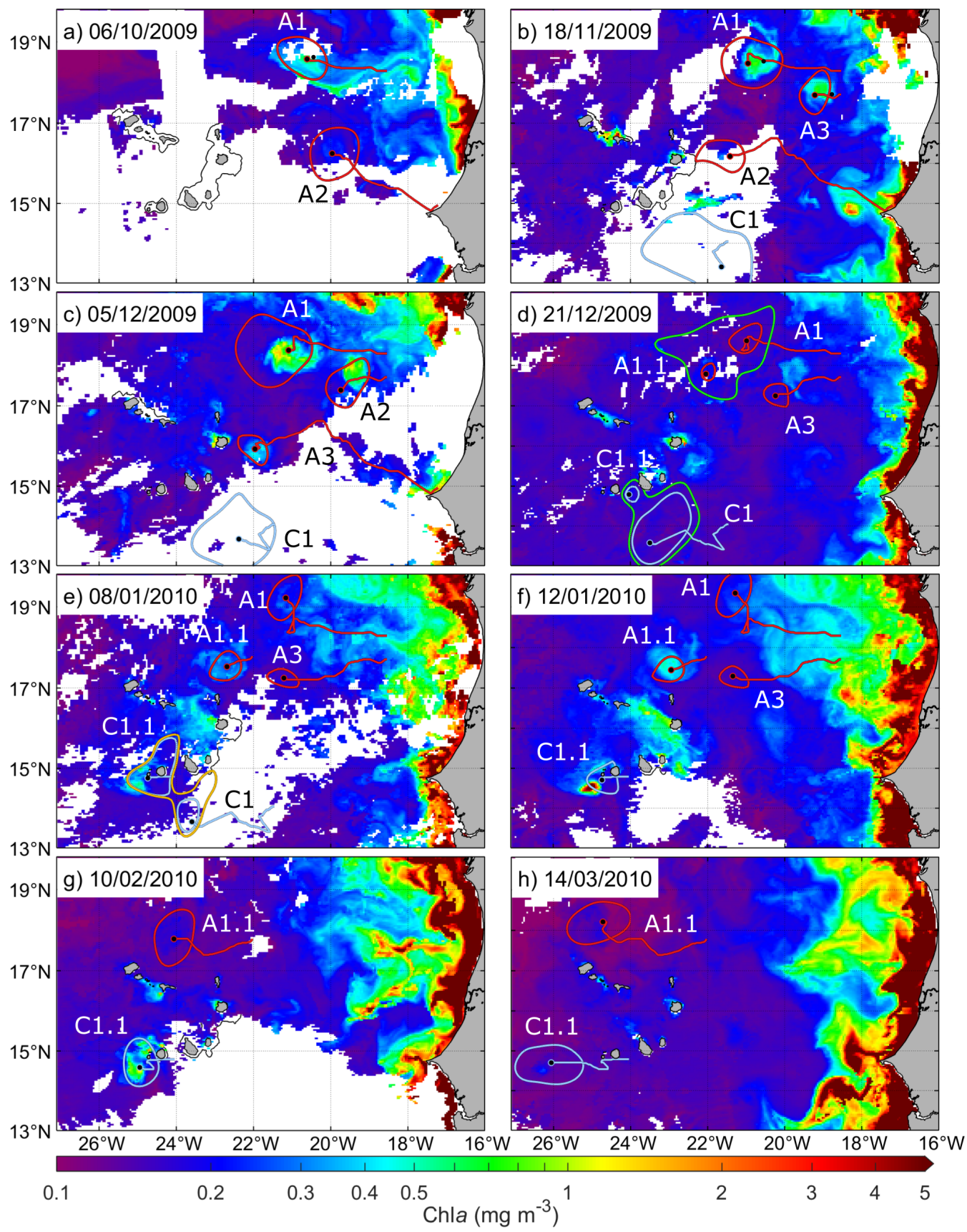

Figure 18: Surface Chl $a$ concentration snapshots (8-day centered moving average), overlapped by anticyclonic (red) and cyclonic (light blue) eddy shapes and trajectories. Black contour around the islands represents the $-2000 \mathrm{~m}$ depth.

ter terminating (Fig. 18d). It has been documented that anticyclonic eddies have the potential to retain and support planktonic communities over many generations, being thus able to enhance larval survival for many invertebrate ${ }_{500}$ served capability of self-promoting primary productivity and considering the fact that most eddies generated in the African coast are highly nonlinear (Fig. 17h), such findings imply that background eddies represent a great medium ${ }_{505}$ western African coast.

Notwithstanding, a new driving mechanism which to present date has only been hypothesized in the region (Chavanne et al., 2002) is presented: the island-induced biological enhancement through eddy-induced injection of deep nutrient-rich water to surface layers, a mechanism often linked to IME (e.g. Basterretxea et al., 2002; Caldeira et al., 2002). As C1 approaches the windward islands from southeast (Fig. 18c) and intersects an island-induced anticyclonic eddy (not identified) in the south of Fogo (Fig. 18d), it splits and gives origin to C1.1. Although related with a background eddy, orographic-disturbed winds are 
likely to have contributed to C1.1's formation, since this560 feature is generated in an area strongly characterised by cyclonic eddies (Fig. 14 upper pannels). The "offspring" C1.1 then incorporates its "parent" C1 and remains stationary in the western flank of Fogo's wake for over a month (Fig. 18e, $\mathrm{f}$ and $\mathrm{g}$ ), giving rise to a very pronounced ${ }^{1565}$ Chl $a$ signal that exceeds $\approx 5 \mathrm{mg} \mathrm{m}^{-3}$. We have strong reasons to believe that island-induced wind shear effects are the driving mechanism for the occurrence of this phytoplankton bloom, manifested in the $\omega_{E k}$ upward velocities exceeding $2 \mathrm{~m} \mathrm{~d}^{-1}$ (not shown).

Such phenomenon has been documented in the lee of Hawaii when Calil et al. (2008) observed the weakening and intensification of a cyclonic eddy as a causative effect of the wind. Further, Hasegawa et al. (2009) inves 4575 tigated the development of phytoplankton blooms in the of an island though modelling efforts and found that the upwelling of nutrients - especially nitrate - provoked by island-induced cyclonic eddies was the driving mechanism. Similar findings have also been extensively reported ${ }_{580}$ in other Macaronesian islands. Using remote sensing tools eral episodes of sub-mesoscale cyclonic eddies generated in the western flank of Madeira Island, accompanied by enhanced levels of Chla. In Canary Islands, Hernández $\$ 585$ León (1991) first documented the accumulation of meso-

1535 zooplankton as a response to IME, but only until later were the enhanced Chl $a$ surface concentrations associated with nutrient-enrichment driven by island-induced cyclonic eddies (Arístegui et al., 1997; Basterretxea et al., 2002). In590 the Azores, however, Caldeira \& Reis (2017) suggested 1540 that the ability of the islands to retain the incoming properties from the impinging flow was the main cause for the observed nutrient and biological enrichment.

IME has often been regarded as an isolated phenomenon, exclusively induced by the islands in the local environment 1545 (Gove et al., 2016). Current findings challenge this idea, as the combination of both remote and island-induced processes often hinders the distinction between them, being therefore deemed as the main drivers for the primary pro $\neq 600$ ductivity in the Cape Verde Archipelago.

\section{Conclusion}

Our study focused on the characterisation of the incoming and localy-generated eddies in the Cape Verde Archipelago between 2003-2014, giving especial attention to the highly complex interaction between background ed-

1555 dies with the islands and consequent implications on the $\mathrm{e}^{610}$ generation and evolution of island-induced eddies. Although many studies have investigated the mechanisms and implications associated with eddy generation in the lee of high-topography deep-water islands, very few have considered the implications of incoming background features in such island-induced processes.

Pronounced long-lived eddy hotspots were detected in the interior of the delimited near-field CV area - mainly the lee of the tallest islands (Fig. 5) - originating a total number of 173 island-induced eddies. Nevertheless, it was also demonstrated that the archipelago is exposed to a remarkable number of incoming background eddies (142) that interact with the islands and consequent islandinduced transformations (Fig. 7), leading to the: i) the blocking and deflection of 58 background eddies; ii) 27 eddy splitting and consequent generation of island-induced eddies; iii) 39 merging events with island-induced eddies or even with their offspring; iv) 12 island-induced wind-shear eddy intensifications; v) and 31 eddy terminations. Most incoming background eddies are generated off the western African coast, mostly near the Cape-Vert headland and between $19^{\circ} \mathrm{W}$ and the archipelago (Fig. 7a). Still, a small number are generated close to the Mauritanian coast, being associated with the seasonal intensification of the southerly along-shore Mauritanian Current (Schütte et al., 2016a). Nonetheless, no significant seasonal pattern is detected in the intersection of background eddies with the archipelago, as their occurrence is ubiquitous throughout the year (Fig. 8). Considering the substantial amount of evidences that support the systematic background eddyisland interactions, one may conclude that many islandinduced eddies are a direct product or by-product of such interaction. For this reason, it is very difficult to determine the nature of the eddies being generated in the archipelago, i.e. from island-induced mechanisms, background eddyisland interaction or even the interaction between background and island-eddies. Therefore, the combination of background eddy-splitting and island-induced wind-shear effects are the main causes for the generation and intensification of local mesoscale eddies.

Besides being a key factor in the generation and intensification of eddies, current results also suggest that islandinduced wind-shear effects may contribute to the containment of cyclonic and anticyclonic eddies in the lee of the mountainous islands of the archipelago (Fig. 14 and $17 \mathrm{~g}$ ). The trajectory cluster formed by deflected background and island-induced anticyclonic eddies in the lee of the leeward islands is the most explicit evidence, as it is characterised by a very distinct south-westward orientation that follows very closely the negative wind-stress curl area. To the best of our knowledge, this is the first time that such mechanism is confirmed by a long record of empirical observations. High values of absolute Ekman pumping velocities (Fig. 15a and b, respectively) also emerge at this location as a result of the interaction between eddies and orographic-disturbed winds. The disparity between the main characteristics of background and island-induced eddies further reflects the influence of orographic-disturbed winds on eddies, mainly for the rotational speeds and associated properties (Table 2 and Fig. 17f, g and h). Island- 
induced topographic effects were also manifested in the mean eddy residence period - higher at the periphery and mean eddy radius - smaller in the immediate vicinity670 of the archipelago (Fig. 17c and e).

Incoming background eddies were demonstrated to have important implications in the local biological realm. Several anticyclonic eddies (October 2009 - March 2010, Fig. 18) were observed transporting Chla-rich water in the direction of Cape Verde, enhancing Chla concentrations in its vicinity. Nevertheless, island-induced processes can 675 also favour local biological productivity, as it was the case of a remarkable Chl a signal west of Fogo (Fig. 18e to g) strongly associated with the self-induced nutrient injection provoked by the interaction of an island-induced $\mathrm{C} 1.1$ with 680 strong wind vorticity. The fact that $\mathrm{C} 1.1$ is related with a background eddy $\mathrm{C} 1$ further reinforces the idea that both fields are intertwined in such a way that hinders the distinction and quantification of individual mechanisms. It685 also challenges the idea that IME is a phenomenon exclusively induced by an island (or group of islands), being thus proposed that IME can be developed and sustained by the combination of local and remote processes.

Finally, we answer the proposed questions of our study: do background incoming eddies have considerable interactions with oceanic islands which have been neglected to present date? Current results strongly suggest that, despite being at $\approx 600 \mathrm{~km}$ distance from the western African coast, background eddies can have considerable implications on island-induced processes occurring in the archipelagoo. On the other hand, island-induced topography effects can modify the characteristics of transiting background eddies, making the Cape Verde Archipelago a perfect location for the study of such processes. Nonetheless, further studies - including in-situ observations in combination with satellite data and coupled numerical simulations - are needed in order to effectively address the various mechanisms behind the interaction of background eddies with the islands $\mathrm{s}_{1710}$ along with the complex island-induced eddy generation processes in the archipelago.

\section{Acknowledgements}

The authors acknowledge Le $\mathrm{Vu}$ et al. (2018) for making AMEDA freely available (ftp://ftp.lmd . polytechniqueт20 $\mathrm{fr} / \mathrm{blevu/AMEDA} /$ ), Copernicus Marine Environment Monitoring Service (CMEMS) for the multimission altimeter satellite gridded ADT and geostrophic velocities (http:// marine.copernicus.eu), NASA Physical Oceanographyy ${ }^{725}$ Distributed Active Archive Center (PO.DAAC) for the QuikScat vector wind observations (http://dx.doi.org/ 10.5067/QSX12-L2B01), GlobCurrent for the ocean surface currents (V2.1 Total 15m; http: //www.globcurrent 1730 org), and NASA's Goddard Space Flight Center, "OceanColor Web" (https://oceancolor.gsfc.nasa.gov) for
Chl $a$ observations. C-2015 ASCAT data were produced by Remote Sensing Systems and sponsored by the NASA Ocean Vector Winds Science Team (http://remss.com). This study was partially supported by the Oceanic Observatory of Madeira (M1420- 01-0145-FEDER-000001- Observatório Oceânico da Madeira-OOM).

\section{References}

Adduce, C., \& Cenedese, C. (2004). An experimental study of a mesoscale vortex colliding with topography of varying geometry in a rotating fluid. Journal of Marine Research, 62, 611-638. doi:10.1357/0022240042387583.

Allis, S. (2015). Diapycnal Mixing Processes and Vertical Velocities within Mesoscale Structures. Ph.D. thesis Universidad de Las Palmas de Gran Canaria.

Alpers, W., Brandt, P., Lazar, A., Dagorne, D., Sow, B., Faye, S., Hansen, M. W., Rubino, A., Poulain, P.-M., \& Brehmer, P. (2013). A small-scale oceanic eddy off the coast of West Africa studied by multi-sensor satellite and surface drifter data. Remote Sensing of Environment, 129, 132-143. doi:10.1016/j.rse.2012.10.032.

Andrade, I., Sangrà, P., Hormazabal, S., \& Correa-Ramirez, M. (2014). Island mass effect in the Juan Fernández Archipelago $\left(33^{\circ} \mathrm{S}\right)$, Southeastern Pacific. Deep Sea Research Part I: Oceanographic Research Papers, 84, 86-99. doi:10.1016/j.dsr.2013.10. 009 .

Andres, M., \& Cenedese, C. (2013). Laboratory experiments and observations of cyclonic and anticyclonic eddies impinging on an island. Journal of Geophysical Research: Oceans, 118, 762-773. doi:10.1002/jgrc. 20081.

Arístegui, J., Sangrá, P., Hernández-León, S., Cantón, M., Hernández-Guerra, A., \& Kerling, J. (1994). Island-induced eddies in the Canary islands. Deep Sea Research Part I: Oceanographic Research Papers, 41, 1509-1525. doi:10.1016/0967-0637(94) 90058-2.

Arístegui, J., Tett, P., Hernández-Guerra, A., Basterretxea, G., Montero, M., Wild, K., Sangrá, P., Hernández-Leon, S., Canton, M., García-Braun, J., Pacheco, M., \& Barton, E. (1997). The influence of island-generated eddies on chlorophyll distribution: a study of mesoscale variation around Gran Canaria. Deep Sea Research Part I: Oceanographic Research Papers, 44, 71-96. doi:10.1016/S0967-0637 (96)00093-3.

Arnault, S. (1987). Tropical Atlantic geostrophic currents and ship drifts. Journal of Geophysical Research, 92, 5076. doi:10.1029/ JC092iC05p05076.

Barkley, R. A. (1972). Johnston Atoll's Wake'. Journal of Marine Research, 30, 201-216.

Barton, E. (2001). Island Wakes. In Encyclopedia of Ocean Sciences (pp. 343-348). Elsevier. doi:10.1016/B978-012374473-9. 00140-5.

Barton, E. D. (1987). Meanders, eddies and intrusions in the thermohaline front off Northwest Africa. Oceanologica acta.Paris, 10, 267-283.

Barton, E. D., Aristegui, J., Tett, P., Canton, M., García-Braun, J., Hernández-León, S., Nykjaer, L., Almeida, C., Almunia, J., Ballesteros, S., Basterretxea, G., Escanez, J., García-Weill, L., Hernández-Guerra, A., López-Laatzen, F., Molina, R., Montero, M. F., Navarro-Peréz, E., Rodríguez, J. M., Van Lenning, K., Vélez, H., \& Wild, K. (1998). The transition zone of the Canary Current upwelling region. Progress in Oceanography, 41, 455-504. doi:10.1016/S0079-6611 (98)00023-8.

Barton, E. D., Basterretxea, G., Flament, P., Mitchelson-Jacob, E. G., Jones, B., Arístegui, J., \& Herrera, F. (2000). Lee region of Gran Canaria. Journal of Geophysical Research: Oceans, 105, 17173-17193. doi:10.1029/2000JC900010.

Basterretxea, G., Barton, E., Tett, P., Sangrá, P., Navarro-Perez, E., \& Arístegui, J. (2002). Eddy and deep chlorophyl maximum response to wind-shear in the lee of Gran Canaria. Deep Sea 
Research Part I: Oceanographic Research Papers, 49, 1087-11011805 doi:10.1016/S0967-0637(02)00009-2.

Bell, P. (1992). Eutrophication and coral reefs-some examples in the Great Barrier Reef lagoon. Water Research, 26, 553-568. doi:10.1016/0043-1354(92) 90228-V.

Brannigan, L. (2016). Intense submesoscale upwelling in anticy 4810 clonic eddies. Geophysical Research Letters, 43, 3360-3369. doi:10.1002/2016GL067926.

Caldeira, R., Groom, S., Miller, P., Pilgrim, D., \& Nezlin, N. (2002). Sea-surface signatures of the island mass effect phenomena around Madeira Island, Northeast Atlantic. Remote Sensing of Environ 4815 ment, 80, 336-360. doi:10.1016/S0034-4257(01)00316-9.

Caldeira, R. M. A., Marchesiello, P., Nezlin, N. P., DiGiacomo, P. M., \& McWilliams, J. C. (2005). Island wakes in the Southern California Bight. Journal of Geophysical Research, 110, C11012. doi:10.1029/2004JC002675

Caldeira, R. M. A., \& Reis, J. C. (2017). The Azores Confluence Zone. Frontiers in Marine Science, 4, 1-14. doi:10.3389/fmars . 2017.00037.

Caldeira, R. M. A., Stegner, A., Couvelard, X., Araújo, I. B., Testor, P., \& Lorenzo, A. (2014). Evolution of an oceanic anticyclones2 in the lee of Madeira Island: In situ and remote sensing survey. Journal of Geophysical Research: Oceans, 119, 1195-1216. doi:10.1002/2013JC009493.

Caldeira, R. M. A., \& Tomé, R. (2013). Wake Response to an Ocean-Feedback Mechanism: Madeira Island Case83 Study. Boundary-Layer Meteorology, 148, 419-436. doi:10.1007/ s10546-013-9817-y.

Calil, P. H., Richards, K. J., Jia, Y., \& Bidigare, R. R. (2008). Eddy activity in the lee of the Hawaiian Islands. Deep Sea Research Part II: Topical Studies in Oceanography, 55, 1179-1194. doi:10 1835 $1016 / \mathrm{j}$.dsr2.2008.01.008

Cenedese, C. (2002). Laboratory experiments on mesoscale vortices colliding with a seamount. Journal of Geophysical Research, 107, 3053. doi:10.1029/2000JC000599.

Cenedese, C. (2005). Laboratory experiments on mesoscale vortices840 interacting with two islands. Journal of Geophysical Research, 110, C09023. doi:10.1029/2004JC002734.

Chaigneau, A., Eldin, G., \& Dewitte, B. (2009). Eddy activity in the four major upwelling systems from satellite altimetry (1992-2007). Progress in Oceanography, 83, 117-123. doi:10.1016/j.pocean 1845 2009.07.012.

Chaigneau, A., Gizolme, A., \& Grados, C. (2008). Mesoscale eddies off Peru in altimeter records: Identification algorithms and eddy spatio-temporal patterns. Progress in Oceanography, 79, 106-119. doi:10.1016/j . pocean . 2008.10.013.

Chang, Y.-C., Chen, G.-Y., Tseng, R.-S., \& Chu, P. C. (2012). Effect of Cylindrically Shaped Atoll on Westward-Propagating Anticyclonic Eddy - A Case Study. IEEE Geoscience and Remote Sensing Letters, 9, 43-46. doi:10.1109/LGRS.2011.2159298.

Chassignet, E. P., \& Cushman-Roisin, B. (1991). On the Influences5 of a Lower Layer on the Propagation of Nonlinear Oceanic Eddies. Journal of Physical Oceanography, 21, 939-957. doi:10. 1175/1520-0485(1991) 021<0939: OTIOAL>2.0.C0;2.

Chavanne, C., Flament, P., Lumpkin, R., Dousset, B., \& Bentamy, A. (2002). Scatterometer observations of wind variations induced 86 by oceanic islands: Implications for wind-driven ocean circulation. Canadian Journal of Remote Sensing, 28, 466-474. doi:10.5589/ m02-047.

Chelton, D. B. (2004). Satellite Measurements Reveal Persistent Small-Scale Features in Ocean Winds. Science, 303, 978-9831865 doi:10.1126/science.1091901.

Chelton, D. B., DeSzoeke, R. A., Schlax, M. G., El Naggar, K. \& Siwertz, N. (1998). Geographical Variability of the First Baroclinic Rossby Radius of Deformation. Journal of Physical Oceanography, 28, 433-460. doi:10.1175/1520-0485(1998) 870 $028<0433$ : GVOTFB>2.0.C0;2.

Chelton, D. B., Schlax, M. G., \& Samelson, R. M. (2011). Global observations of nonlinear mesoscale eddies. Progress in Oceanography, 91, 167-216. doi:10.1016/j.pocean.2011.01.002.

Chopra, K. P., \& Hubert, L. F. (1964). Kármán Vortex-Streets875 in Earth's Atmosphere. Nature, 203, 1341-1343. doi:10.1038/ $2031341 \mathrm{b0}$

Church, J. A., \& White, N. J. (2011). Sea-Level Rise from the Late 19th to the Early 21st Century. Surveys in Geophysics, 32, 585602. doi:10.1007/s10712-011-9119-1.

Condie, S., \& Condie, R. (2016). Retention of plankton within ocean eddies. Global Ecology and Biogeography, 25, 1264-1277. doi:10. 1111/geb. 12485

Coutis, P., \& Middleton, J. (2002). The physical and biological impact of a small island wake in the deep ocean. Deep Sea Research Part I: Oceanographic Research Papers, 49, 1341-1361. doi:10.1016/S0967-0637(02)00029-8.

Couvelard, X., Caldeira, R., Araújo, I., \& Tomé, R. (2012). Wind mediated vorticity-generation and eddy-confinement, leeward of the Madeira Island: 2008 numerical case study. Dynamics of Atmospheres and Oceans, 58, 128-149. doi:10.1016/j.dynatmoce. 2012.09 .005$.

Cushman-Roisin, B., Tang, B., \& Chassignet, E. P. (1990). Westward Motion of Mesoscale Eddies. Journal of Physical Oceanography, 20 , 758-768. doi:10.1175/1520-0485(1990) 020<0758: WMOME>2.0. $\mathrm{CO} ; 2$.

Dandonneau, Y., \& Charpy, L. (1985). An empirical approach to the island mass effect in the south tropical Pacific based on sea surface chlorophyll concentrations. Deep Sea Research Part A. Oceanographic Research Papers, 32, 707-721. doi:10.1016/ 0198-0149 (85) 90074-3

Demarcq, H., \& Somoue, L. (2015). Phytoplankton and primary productivity off Northwest Africa. In L. Valdés, \& Déniz-González (Eds.), Oceanographic and biological features in the Canary Current Large Marine Ecosystem chapter 4.4. (pp. 161-171). Paris: IOC-UNESCO volume 115. arXiv: 2710

DGA, C. (2004). Livro branco sobre o estado do ambiente em cabo verde.

Dickey, T. D., Nencioli, F., Kuwahara, V. S., Leonard, C., Black, W., Rii, Y. M., Bidigare, R. R., \& Zhang, Q. (2008). Physical and bio-optical observations of oceanic cyclones west of the island of Hawai'i. Deep Sea Research Part II: Topical Studies in Oceanography, 55, 1195-1217. doi:10.1016/j.dsr2.2008.01.006. Dong, C., Mavor, T., Nencioli, F., Jiang, S., Uchiyama, Y., McWilliams, J. C., Dickey, T., Ondrusek, M., Zhang, H., \& Clark, D. K. (2009). An oceanic cyclonic eddy on the lee side of Lanai Island, Hawai'i. Journal of Geophysical Research, 114, C10008. doi:10.1029/2009JC005346

Dong, C., McWilliams, J. C., \& Shchepetkin, A. F. (2007). Island Wakes in Deep Water. Journal of Physical Oceanography, 37, 962-981. doi:10.1175/JP03047.1.

Doty, M. S., \& Oguri, M. (1956). The Island Mass Effect. ICES Journal of Marine Science, 22, 33-37. doi:10.1093/icesjms/22 . 1.33.

Dufois, F., Hardman-Mountford, N. J., Greenwood, J., Richardson, A. J., Feng, M., \& Matear, R. J. (2016). Anticyclonic eddies are more productive than cyclonic eddies in subtropical gyres because of winter mixing. Science Advances, 2, e1600282-e1600282. doi:10.1126/sciadv. 1600282

Emery, W. J., Meincke, J. (1986). Global water masses: summary and review. Oceanologica Acta, 9, 383-391.

Faghmous, J. H., Frenger, I., Yao, Y., Warmka, R., Lindell, A., \& Kumar, V. (2015). A daily global mesoscale ocean eddy dataset from satellite altimetry. Scientific Data, 2, 150028. doi:10.1038/ sdata.2015.28.

Faye, S., Lazar, A., Sow, B. A., \& Gaye, A. T. (2015). A model study of the seasonality of sea surface temperature and circulation in the Atlantic North-eastern Tropical Upwelling System. Frontiers in Physics, 3, 1-20. doi:10.3389/fphy.2015.00076

Fernandes, M., Marçal, A., Azevedo, J., Santos, A., \& Peliz, A. (2000). Fisheries monitoring in the cabo verde region using ers data. In Proceedings of the ERS-ENVISAT Symposium, Looking down to Earth in the New Millenium.

Fernandes, M. J., Lázaro, C., Santos, A. M. P., \& Oliveira, P. (2005). Oceanographic characterisation of the cape verde region using multisensor data. In Proceedings of the ENVISAT and ERS Sym- 
posium, Salzburg, 6-10 September 2004 (pp. 815-824). volume 2004.

Fiedler, B., Grundle, D. S., Schütte, F., Karstensen, J., Löscher, C. R., Hauss, H., Wagner, H., Loginova, A., Kiko, R., Silva, P.1950 Tanhua, T., \& Körtzinger, A. (2016). Oxygen utilization and downward carbon flux in an oxygen-depleted eddy in the eastern tropical North Atlantic. Biogeosciences, 13, 5633-5647. doi:10. 5194/bg-13-5633-2016.

Fischer, G., Karstensen, J., Romero, O., Baumann, K.-H., Donner1955 B., Hefter, J., Mollenhauer, G., Iversen, M., Fiedler, B., Monteiro, I., \& Körtzinger, A. (2016). Bathypelagic particle flux signatures from a suboxic eddy in the oligotrophic tropical North Atlantic: production, sedimentation and preservation. Biogeosciences, 13, 3203-3223. doi:10.5194/bg-13-3203-2016.

Fischer, G., Reuter, C., Karakas, G., Nowald, N., \& Wefer, G. (2009). Offshore advection of particles within the Cape Blanc filament, Mauritania: Results from observational and modelling studies. Progress in Oceanography, 83, 322-330. doi:10.1016/j.pocean. 2009.07.023.

Fore, A. G., Stiles, B. W., Chau, A. H., Williams, B. A., Dunbar, R. S., \& Rodriguez, E. (2014). Point-Wise Wind Retrieval and Ambiguity Removal Improvements for the QuikSCAT Climatological Data Set. IEEE Transactions on Geoscience and Remote Sensing, 52, 51-59. doi:10.1109/TGRS.2012.2235843.

Fratantoni, D. M. (2001). North Atlantic surface circulation during the 1990's observed with satellite-tracked drifters. Journal of Geophysical Research: Oceans, 106, 22067-22093. doi:10.1029/ 2000JC000730.

Fu, L.-L., \& Holt, B. (1983). Some examples of detection of 975 oceanic mesoscale eddies by the SEASAT synthetic-aperture radar. Journal of Geophysical Research, 88, 1844. doi:10.1029/ JC088iC03p01844.

Gabric, A. J., Garcia, L., Van Camp, L., Nykjaer, L., Eifler, W., \& Schrimpf, W. (1993). Offshore export of shelf production in the980 Cape Blanc (Mauritania) giant filament as derived from coastal zone color scanner imagery. Journal of Geophysical Research: Oceans, 98, 4697-4712. doi:10.1029/92JC01714.

García-Weil, L., Ramos, A. G., Coca, J., \& Redondo, A. (2014). Mesoscale dynamics in the canary islands area as observed through985 complementary remote sensing techniques. In Remote Sensing of the African Seas (pp. 97-118). Springer.

Gaube, P., Chelton, D. B., Samelson, R. M., Schlax, M. G., \& O'Neill, L. W. (2015). Satellite Observations of Mesoscale EddyInduced Ekman Pumping. Journal of Physical Oceanography, 451990 104-132. doi:10.1175/JP0-D-14-0032.1.

Gaube, P., Chelton, D. B., Strutton, P. G., \& Behrenfeld, M. J. (2013). Satellite observations of chlorophyll, phytoplankton biomass, and Ekman pumping in nonlinear mesoscale eddies. Journal of Geophysical Research: Oceans, 118, 6349-63701995 doi:10.1002/2013JC009027.

Gaube, P., McGillicuddy, D. J., Chelton, D. B., Behrenfeld, M. J., \& Strutton, P. G. (2014). Regional variations in the influence of mesoscale eddies on near-surface chlorophyll. Journal of Geophysical Research: Oceans, 119, 8195-8220. doi:10.1002/2000 2014JC010111.

Gill, A. E. (1982). Atmosphere-ocean dynamics volume 30 of International Geophysical Series. 111 Fifth Avenue, New York, New York: Academic Press.

Gove, J. M., McManus, M. A., Neuheimer, A. B., Polovina, J. J.2005 Drazen, J. C., Smith, C. R., Merrifield, M. A., Friedlander, A. M., Ehses, J. S., Young, C. W., Dillon, A. K., \& Williams, G. J. (2016). Near-island biological hotspots in barren ocean basins. Nature Communications, 7, 10581. doi:10.1038/ncomms10581.

Hafner, J., \& Xie, S.-P. (2003). Far-Field Simulation of the Hawaiiarro10 Wake: Sea Surface Temperature and Orographic Effects*. Journal of the Atmospheric Sciences, 60, 3021-3032. doi:10.1175/ $1520-0469$ (2003) $060<3021$ : FSOTHW $>2$. 0. CO 2 .

Hagen, E. (2001). Northwest African upwelling scenario. Oceanologica Acta, 24, 113-128. doi:10.1016/S0399-1784(00)01110-5. 2015

Hamner, W. M., \& Hauri, I. R. (1981). Effects of island mass: Water flow and plankton pattern around a reef in the Great Barrier Reef lagoon, Australia1. Limnology and Oceanography, 26, 1084-1102. doi:10.4319/1o.1981.26.6.1084.

Hasegawa, D., Lewis, M. R., \& Gangopadhyay, A. (2009). How islands cause phytoplankton to bloom in their wakes. Geophysical Research Letters, 36, 2-5. doi:10.1029/2009GL039743.

Hauss, H., Christiansen, S., Schütte, F., Kiko, R., Edvam Lima, M., Rodrigues, E., Karstensen, J., Löscher, C. R., Körtzinger, A., \& Fiedler, B. (2016). Dead zone or oasis in the open ocean? Zooplankton distribution and migration in low-oxygen modewater eddies. Biogeosciences, 13, 1977-1989. doi:10.5194/ bg-13-1977-2016.

Helmke, P., Romero, O., \& Fischer, G. (2005). Northwest African upwelling and its effect on offshore organic carbon export to the deep sea. Global Biogeochemical Cycles, 19, n/a-n/a. doi:10. 1029/2004GB002265.

Hernández-León, S. (1991). Accumulation of mesozooplankton in a wake area as a causative mechanism of the ?island-mass effect? Marine Biology, 109, 141-147. doi:10.1007/BF01320241.

Heywood, K. J., Barton, E. D., \& Simpson, J. H. (1990). The effects of flow disturbance by an oceanic island. Journal of Marine Research, 48, 55-73. doi:10.1357/002224090784984623.

Hoffman, R. N., \& Leidner, S. M. (2005). An Introduction to the Near-Real-Time QuikSCAT Data. Weather and Forecasting, 20, 476-493. doi:10.1175/WAF841.1.

Holland, C. L., \& Mitchum, G. T. (2001). Propagation of Big Island eddies. Journal of Geophysical Research: Oceans, 106, 935-944. doi:10.1029/2000JC000231

Hwang, D.-W., Lee, Y.-W., \& Kim, G. (2005). Large submarine groundwater discharge and benthic eutrophication in Bangdu Bay on volcanic Jeju Island, Korea. Limnology and Oceanography, 50 , 1393-1403. doi:10.4319/1o.2005.50.5.1393.

Ioannou, A., Stegner, A., Le Vu, B., Taupier-Letage, I., \& Speich, S. (2017). Dynamical Evolution of Intense Ierapetra Eddies on a 22 Year Long Period. Journal of Geophysical Research: Oceans, 122, 9276-9298. doi:10.1002/2017JC013158.

Jia, Y., Calil, P. H. R., Chassignet, E. P., Metzger, E. J., Potemra, J. T., Richards, K. J., \& Wallcraft, A. J. (2011). Generation of mesoscale eddies in the lee of the Hawaiian Islands. Journal of Geophysical Research, 116, C11009. doi:10.1029/2011JC007305.

Jiménez, B., Sangrà, P., \& Mason, E. (2008). A numerical study of the relative importance of wind and topographic forcing on oceanic eddy shedding by tall, deep water islands. Ocean Modelling, 22, 146-157. doi:10.1016/j.ocemod.2008.02.004.

Karimova, S. (2012). Spiral eddies in the Baltic, Black and Caspian seas as seen by satellite radar data. Advances in Space Research, 50,1107-1124. doi:10.1016/j.asr.2011.10.027.

Karstensen, J., Fiedler, B., Schütte, F., Brandt, P., Körtzinger, A., Fischer, G., Zantopp, R., Hahn, J., Visbeck, M., \& Wallace, D. (2015). Open ocean dead zones in the tropical North Atlantic Ocean. Biogeosciences, 12, 2597-2605. doi:10.5194/ bg-12-2597-2015.

Karstensen, J., Schütte, F., Pietri, A., Krahmann, G., Fiedler, B., Grundle, D., Hauss, H., Körtzinger, A., Löscher, C. R., Testor, P., Vieira, N., \& Visbeck, M. (2017). Upwelling and isolation in oxygen-depleted anticyclonic modewater eddies and implications for nitrate cycling. Biogeosciences, 14, 2167-2181. doi:10.5194/ bg-14-2167-2017.

Kostianoy, A., \& Zatsepin, A. (1996). The West African coastal upwelling filaments and cross-frontal water exchange conditioned by them. Journal of Marine Systems, 7, 349-359. doi:10.1016/ 0924-7963 (95) 00029-1.

Kundu, P., \& Cohen, L. (1990). Fluid mechanics. In Fluid mechanics (p. 638). Academic Press, San Diego, Calif.

Large, W. G., \& Pond, S. (1981). Open Ocean Momentum Flux Measurements in Moderate to Strong Winds. Journal of Physical Oceanography, 11, 324-336. doi:10.1175/1520-0485(1981) $011<0324$ : OOMFMI $>2$. 0. CO 2 .

Lathuilière, C., Echevin, V., \& Lévy, M. (2008). Seasonal and intraseasonal surface chlorophyll-a variability along the northwest African coast. Journal of Geophysical Research, 113, C05007. doi:10.1029/2007 JC004433. 
Lázaro, C., Fernandes, M. J., Santos, A. M. P., \& Oliveira, P. (2005). Seasonal and interannual variability of surface circulazogo tion in the Cape Verde region from 8 years of merged T/P and ERS-2 altimeter data. Remote Sensing of Environment, 98, 4562. doi:10.1016/j.rse.2005.06.005.

Le Vu, B., Stegner, A., \& Arsouze, T. (2018). Angular Momentum Eddy Detection and Tracking Algorithm (AMEDA) and 095 Its Application to Coastal Eddy Formation. Journal of Atmospheric and Oceanic Technology, 35, 739-762. doi:10.1175/ JTECH-D-17-0010.1.

Löscher, C. R., Fischer, M. A., Neulinger, S. C., Fiedler, B., Philippi, M., Schütte, F., Singh, A., Hauss, H., Karstensen, J., Körtzingerz100 A., Künzel, S., \& Schmitz, R. A. (2015). Hidden biosphere in an oxygen-deficient Atlantic open-ocean eddy: future implications of ocean deoxygenation on primary production in the eastern tropical North Atlantic. Biogeosciences, 12, 7467-7482. doi:10.5194/bg-12-7467-2015.

Lozier, M. S., Owens, W. B., \& Curry, R. G. (1995). The climatology of the North Atlantic. Progress in Oceanography, 36, 1-44. doi:10.1016/0079-6611(95)00013-5.

Mahadevan, A., Thomas, L. N., \& Tandon, A. (2008). Comment on "Eddy/Wind Interactions Stimulate Extraordinary Midz110 Ocean Plankton Blooms". Science, 320, 448b-448b. doi:10.1126/ science.1152111.

Martin, A. P., \& Richards, K. J. (2001). Mechanisms for vertical nutrient transport within a North Atlantic mesoscale eddy. Deep Sea Research Part II: Topical Studz115 ies in Oceanography, 48, 757-773. doi:10.1016/S0967-0645(00) 00096-5. arXiv: arXiv:1011.1669v3.

McGillicuddy, D. J. (2016). Mechanisms of Physical-BiologicalBiogeochemical Interaction at the Oceanic Mesoscale. Annual Review of Marine Science, 8, 125-159. doi:10.1146/k120 annurev-marine-010814-015606.

McGillicuddy, D. J., Anderson, L. A., Bates, N. R., Bibby, T., Buesseler, K. O., Carlson, C. A., Davis, C. S., Ewart, C., Falkowski, P. G., Goldthwait, S. A., Hansell, D. A., Jenkins, W. J., Johnson, R., Kosnyrev, V. K., Ledwell, J. R., Li, Q. P., Siegel, D. A.2125 \& Steinberg, D. K. (2007). Eddy/Wind Interactions Stimulate Extraordinary Mid-Ocean Plankton Blooms. Science, 316, 10211026. doi:10.1126/science.1136256.

McGillicuddy, D. J., Ledwell, J. R., \& Anderson, L. A. (2008). Response to Comment on "Eddy/Wind Interactions Stimulate Exz130 traordinary Mid-Ocean Plankton Blooms". Science, 320, 448c448c. doi:10.1126/science.1148974.

Meunier, T., Barton, E. D., Barreiro, B., \& Torres, R. (2012). Upwelling filaments off Cap Blanc: Interaction of the NW African upwelling current and the Cape Verde frontal zone eddy field 3135 Journal of Geophysical Research: Oceans, 117, n/a-n/a. doi:10. 1029/2012JC007905.

Mittelstaedt, E. (1983). The upwelling area off Northwest Africa-A description of phenomena related to coastal upwelling. Progress in Oceanography, 12, 307-331. doi:10.1016/0079-6611(83) 90012-52140

Mittelstaedt, E. (1991). The ocean boundary along the northwest African coast: Circulation and oceanographic properties at the sea surface. Progress in Oceanography, 26, 307-355. doi:10.1016/ 0079-6611 (91) 90011-A.

Mkhinini, N., Coimbra, A. L. S., Stegner, A., Arsouze, T., Taupierz145 Letage, I., \& Béranger, K. (2014). Long-lived mesoscale eddies in the eastern Mediterranean Sea: Analysis of 20 years of AVISO geostrophic velocities. Journal of Geophysical Research: Oceans, 119, 8603-8626. doi:10.1002/2014JC010176.

Moroni, D., Stiles, B., \& Fore, A. (2013). QuikSCAT Level 2B Verz150 sion 3 - Guide Document. URL: ftp://podaac.jpl.nasa.gov/ allData/quikscat/L2B12/docs/qscat_12b_v3_ug_v1_0.pdf.

Morrow, R. (2004). Divergent pathways of cyclonic and anti-cyclonic ocean eddies. Geophysical Research Letters, 31, L24311. doi:10. 1029/2004GL020974.

Nencioli, F., Kuwahara, V. S., Dickey, T. D., Rii, Y. M., \& Bidigare, R. R. (2008). Physical dynamics and biological implications of a mesoscale eddy in the lee of Hawai'i: Cyclone Opal observations during E-Flux III. Deep Sea Research Part II: Topical Studies in
Oceanography, 55, 1252-1274. doi:10.1016/j.dsr2.2008.02.003. Nieto, K., Demarcq, H., \& McClatchie, S. (2012). Mesoscale frontal structures in the Canary Upwelling System: New front and filament detection algorithms applied to spatial and temporal patterns. Remote Sensing of Environment, 123, 339-346. doi:10.1016/j.rse.2012.03.028.

Niiler, P. P. (1969). On the Ekman divergence in an oceanic jet. Journal of Geophysical Research, 74, 7048-7052. doi:10.1029/ JC074i028p07048.

Nof, D., \& Simon, L. M. (1987). Laboratory Experiments on the Merging of Nonlinear Anticyclonic Eddies. Journal of Physical Oceanography, 17, 343-357. doi:10.1175/1520-0485(1987) $017<0343$ :LEOTMO>2.0.CO; 2 .

Nykjær, L., \& Van Camp, L. (1994). Seasonal and interannual variability of coastal upwelling along northwest Africa and Portugal from 1981 to 1991. Journal of Geophysical Research, 99, 14197. doi:10.1029/94JC00814.

Ohde, T., \& Siegel, H. (2010). Biological response to coastal upwelling and dust deposition in the area off Northwest Africa. Continental Shelf Research, 30, 1108-1119. doi:10.1016/j.csr.2010. 02.016.

Ould-Dedah, S., Wiseman, W. J., \& Shaw, R. F. (1999). Spatial and temporal trends of sea surface temperature in the northwest African region. Oceanologica Acta, 22, 265-279. doi:10.1016/ S0399-1784 (99) 80051-6.

Pascual, A., Faugère, Y., Larnicol, G., \& Le Traon, P.-Y. (2006). Improved description of the ocean mesoscale variability by combining four satellite altimeters. Geophysical Research Letters, 33, L02611. doi:10.1029/2005GL024633.

Pastor, M. V., Pelegrí, J. L., Hernández-Guerra, A., Font, J., Salat, J., \& Emelianov, M. (2008). Water and nutrient fluxes off Northwest Africa. Continental Shelf Research, 28, 915-936. doi:10.1016/j.csr.2008.01.011.

Pattiaratchi, C., James, A., \& Collins, M. (1987). Island wakes and headland eddies: A comparison between remotely sensed data and laboratory experiments. Journal of Geophysical Research, 92, 783. doi:10.1029/JC092iC01p00783.

Pelegrí, J., Marrero-Díaz, A., \& Ratsimandresy, A. (2006). Nutrient irrigation of the North Atlantic. Progress in Oceanography, 70, 366-406. doi:10.1016/j.pocean.2006.03.018.

Pelegrí, J. L., \& Peña-Izquierdo, J. (2015). Inorganic nutrients and dissolved oxygen in the Canary Current Large Marine Ecosystem. In L. Valdés, \& I. Déniz-González (Eds.), Oceanographic and biological features in the Canary Current Large Marine Ecosystem (pp. 133-142). IOC-UNESCO, Paris volume 115.

Pérez-Rodríguez, P., Pelegrí, J. L., \& Marrero-Díaz, A. (2001). Dynamical characteristics of the Cape Verde frontal zone. Scientia Marina, 65, 241-250. doi:10.3989/scimar.2001.65s1241.

Piedeleu, M., Sangrà, P., Sánchez-Vidal, A., Fabrés, J., Gordo, C., \& Calafat, A. (2009). An observational study of oceanic eddy generation mechanisms by tall deep-water islands (Gran Canaria). Geophysical Research Letters, 36, L14605. doi:10.1029/ 2008GL037010.

Polito, P. S., \& Sato, O. T. (2015). Do eddies ride on Rossby waves? Journal of Geophysical Research: Oceans, 120, 54175435. doi:10.1002/2015JC010737.

Pradhan, Y., Lavender, S. J., Hardman-Mountford, N. J., \& Aiken, J. (2006). Seasonal and inter-annual variability of chlorophyll-a concentration in the Mauritanian upwelling: Observation of an anomalous event during 1998-1999. Deep Sea Research Part II: Topical Studies in Oceanography, 53, 1548-1559. doi:10.1016/j. dsr2.2006.05.016.

Pullen, J., Doyle, J. D., May, P., Chavanne, C., Flament, P., \& Arnone, R. A. (2008). Monsoon surges trigger oceanic eddy formation and propagation in the lee of the Philippine Islands. Geophysical Research Letters, 35, n/a-n/a. doi:10.1029/2007GL033109.

Ramalho, R. A. S. (2011). Building the Cape Verde Islands. Berlin, Heidelberg: Springer Berlin Heidelberg. doi:10.1007/ 978-3-642-19103-9.

Ricciardulli, L. (2016). ASCAT on MetOp-A Data Product Update Notes. Technical Report RSS Technical Report: 040416 Re- 
mote Sensing Systems. URL: http://images.remss.com/papers/ rsstech/2016_040416_RSS_ASCAT_V2_update.pdf.

Richardson, P. L. (1983). Eddy kinetic energy in the North Atlantic from surface drifters. Journal of Geophysical Research, 88, 4355. doi:10.1029/JC088iC07p04355.

Robinson, I. S. (2010). Discovering the Ocean from Space. Berlin, Heidelberg: Springer Berlin Heidelberg. doi:10.1007/ 978-3-540-68322-3.

Romero, O. E., Fischer, G., Karstensen, J., \& Cermeño, P. (2016). Eddies as trigger for diatom productivity in the open-ocean Northz240 east Atlantic. Progress in Oceanography, 147, 38-48. doi:10. 1016/j.pocean.2016.07.011.

Sangrà, P., Auladell, M., Marrero-Díaz, A., Pelegrí, J., Fraile-Nuez, E., Rodríguez-Santana, A., Martín, J., Mason, E., \& HernándezGuerra, A. (2007). On the nature of oceanic eddies shed by the245 Island of Gran Canaria. Deep Sea Research Part I: Oceanographic Research Papers, 54, 687-709. doi:10.1016/j.dsr.2007.02.004.

Sangrà, P., Pascual, A., Rodríguez-Santana, Á., Machín, F., Mason, E., McWilliams, J. C., Pelegrí, J. L., Dong, C., Rubio, A., Arístegui, J., Marrero-Díaz, Á., Hernández-Guerra, A., Martínezz250 Marrero, A., \& Auladell, M. (2009). The Canary Eddy Corridor: A major pathway for long-lived eddies in the subtropical North Atlantic. Deep Sea Research Part I: Oceanographic Research Papers, 56, 2100-2114. doi:10.1016/j.dsr.2009.08.008.

Sangrà, P., Pelegrí, J. L., Hernández-Guerra, A., Arregui, I., Martínz255 J. M., Marrero-Díaz, A., Martínez, A., Ratsimandresy, A. W., \& Rodríguez-Santana, A. (2005). Life history of an anticyclonic eddy. Journal of Geophysical Research: Oceans, 110, 1-19. doi:10.1029/2004JC002526.

Savtchenko, A., Ouzounov, D., Ahmad, S., Acker, J., Leptoukh2260 G., Koziana, J., \& Nickless, D. (2004). Terra and Aqua MODIS products available from NASA GES DAAC. Advances in Space Research, 34, 710-714. doi:10.1016/j.asr.2004.03.012.

Schütte, F., Brandt, P., \& Karstensen, J. (2016a). Occurrence and characteristics of mesoscale eddies in the tropical northeastz265 ern Atlantic Ocean. Ocean Science, 12, 663-685. doi:10.5194/ os-12-663-2016.

Schütte, F., Karstensen, J., Krahmann, G., Hauss, H., Fiedler, B., Brandt, P., Visbeck, M., \& Körtzinger, A. (2016b). Characterization of "dead-zone" eddies in the eastern tropical North Atlantic2270 Biogeosciences, 13, 5865-5881. doi:10.5194/bg-13-5865-2016.

Siedler, G., Zangenberg, N., Onken, R., \& Morlière, A. (1992). Seasonal changes in the tropical Atlantic circulation: Observation and simulation of the Guinea Dome. Journal of Geophysical Research, 97, 703. doi:10.1029/91JC02501.

Simmons, H. L., \& Nof, D. (2000). Islands as eddy splitters. Journal of Marine Research, 58, 919-956. doi:10.1357/ 002224000763485755.

Simmons, H. L., \& Nof, D. (2002). The Squeezing of Eddies through Gaps. Journal of Physical Oceanography, 32, 314-335. doi:10 2280 1175/1520-0485(2002)032<0314: TSOETG>2.0. CO 2 .

Spedding, G. R. (2014). Wake Signature Detection. Annual Review of Fluid Mechanics, 46, 273-302. doi:10.1146/ annurev-fluid-011212-140747.

Stegner, A. (2014). Oceanic Island Wake Flows in the Laboratory. (pp. 265-276). doi:10.1002/9781118856024.ch14.

Stern, M. E. (1965). Interaction of a uniform wind stress with a geostrophic vortex. Deep Sea Research and Oceanographic Abstracts, 12, 355-367. doi:10.1016/0011-7471(65)90007-0.

Stern, M. E. (2000). Scattering of an eddy advected by a current towards a topographic obstacle. Journal of Fluid Mechanics, 402, S0022112099006795. doi:10.1017/S0022112099006795.

Stramma, L., Hüttl, S., \& Schafstall, J. (2005). Water masses and currents in the upper tropical northeast Atlantic off northwest Africa. Journal of Geophysical Research, 110, C12006. doi:10. 1029/2005JC002939.

Stramma, L., \& Schott, F. (1999). The mean flow field of the tropical Atlantic Ocean. Deep Sea Research Part II: Topical Studies in Oceanography, 46, 279-303. doi:10.1016/S0967-0645(98) 00109-X.
Atlantic subtropical gyre. Journal of Geophysical Research, 93, 8111. doi:10.1029/JC093iC07p08111.

Tait, D. R., Erler, D. V., Santos, I. R., Cyronak, T. J., Morgenstern, U., \& Eyre, B. D. (2014). The influence of groundwater inputs and age on nutrient dynamics in a coral reef lagoon. Marine Chemistry, 166, 36-47. doi:10.1016/j.marchem.2014.08.004.

Tanabe, A., \& Cenedese, C. (2008). Laboratory experiments on mesoscale vortices colliding with an island chain. Journal of Geophysical Research, 113, C04022. doi:10.1029/2007JC004322.

Tilstone, G. H., Angel-Benavides, I. M., Pradhan, Y., Shutler, J. D., Groom, S., \& Sathyendranath, S. (2011). An assessment of chlorophyll-a algorithms available for SeaWiFS in coastal and open areas of the Bay of Bengal and Arabian Sea. Remote Sensing of Environment, 115, 2277-2291. doi:10.1016/j.rse.2011. 04.028

Tomczak, M. (1988). Island wakes in deep and shallow water. Journal of Geophysical Research, 93, 5153. doi:10.1029/ JC093iC05p05153.

Trenberth, K. E., Large, W. G., \& Olson, J. G. (1990). The Mean Annual Cycle in Global Ocean Wind Stress. Journal of Physical Oceanography, 20, 1742-1760. doi:10.1175/1520-0485(1990) $020<1742$ : TMACIG $>2.0$. CO 2 .

Van Camp, L., Nykjaer, L., Mittelstaedt, E., \& Schlittenhardt, P. (1991). Upwelling and boundary circulation off Northwest Africa as depicted by infrared and visible satellite observations. Progress in Oceanography, 26, 357-402. doi:10.1016/ 0079-6611(91) 90012-B.

Varela-Lopes, G. E., \& Molion, L. C. B. (2014). Precipitation Patterns in Cape Verde Islands: Santiago Island Case Study. Atmospheric and Climate Sciences, 04, 854-865. doi:10.4236/acs . 2014.45075

Wilson, C. (2016). Does the wind systematically energize or damp ocean eddies? doi:10.1002/2016GL072215.

Xu, C., Zhai, X., \& Shang, X.-d. (2016). Work done by atmospheric winds on mesoscale ocean eddies. Geophysical Research Letters, 43, 12,174-12,180. doi:10.1002/2016GL071275.

Yamagata, T., \& Iizuka, S. (1995). Simulation of the tropical thermal domes in the Atlantic. A seasonal cycle.

Yamaguchi, S., \& Kawamura, H. (2009). SAR-imaged spiral eddies in Mutsu Bay and their dynamic and kinematic models. Journal of Oceanography, 65, 525-539. doi:10.1007/s10872-009-0045-5.

Yang, S., Xing, J., Chen, D., \& Chen, S. (2017). A modelling study of eddy-splitting by an island/seamount. Ocean Science, 13, 837849. doi:10.5194/os-13-837-2017.

Yoshida, S., Qiu, B., \& Hacker, P. (2010). Wind-generated eddy characteristics in the lee of the island of Hawaii. Journal of Geophysical Research, 115, C03019. doi:10.1029/2009JC005417.

Zenk, W., Klein, B., \& Schroder, M. (1991). Cape Verde Frontal Zone. Deep Sea Research Part A. Oceanographic Research Papers, 38, S505-S530. doi:10.1016/S0198-0149(12)80022-7.

Zhang, D., McPhaden, M. J., \& Johns, W. E. (2003). Observational Evidence for Flow between the Subtropical and Tropical Atlantic: The Atlantic Subtropical Cells*. Journal of Physical Oceanography, 33, 1783-1797. doi:10.1175/2408.1. 